\title{
A new profile control design based on quantitative identification of steam breakthrough channel in heavy oil reservoirs
}

\author{
Chuan Lu $\cdot$ Huiqing Liu $\cdot$ Zhanxi Pang $\cdot$ \\ Xiaohu Dong $\cdot$ Wei Xiu
}

Received: 25 April 2013/Accepted: 28 August 2013/Published online: 13 September 2013

(C) The Author(s) 2013. This article is published with open access at Springerlink.com

\begin{abstract}
Steam breakthrough has a great negative influence on the development of steam flooding in heavy oil reservoirs. In this article, a new profile control design based on quantitative identification of steam breakthrough channel is introduced. Firstly, dual-sandpack experiments are conducted to study the characteristics and influencing factors of steam breakthrough. Then based on the experimental results as well as pretreatment and combination of geological parameters and production data, comprehensive identification parameter (CIP) is achieved through the analytic hierarchy process to quantitatively describe the degree of steam breakthrough. Afterward, the breakthrough types of production wells are determined by CIP and the volume of breakthrough channels and profile control parameters among the injector and the producers are calculated according to the tapering distribution of steam breakthrough in the process of steam flooding in heavy oil reservoirs. The experiment results show that there exists a large difference between breakthrough channels and nonbreakthrough areas in temperature and oil recovery. Permeability contrast is an important factor, which influences the direction of steam breakthrough, and temperature has a great correlation with oil recovery under the heterogeneous condition. The determination of CIP is an attempt to quantify the degree of breakthrough and it combines many factors, which show the difference between the injector and the producer, as well as the difference between producers. All producers of the steam flooding well group can be divided into complete breakthrough wells with CIP over
\end{abstract}

C. Lu $(\bowtie) \cdot$ H. Liu $\cdot$ Z. Pang $\cdot$ X. Dong $\cdot$ W. Xiu MOE Key Laboratory of Petroleum Engineering, China University of Petroleum, Beijing. No. 18 Fuxue Road, Changping, District, Beijing 102249, People's Republic of China e-mail: luchuan2106@163.com
0.5 and incomplete breakthrough wells with CIP below 0.5 for calculating conveniently. Based on the tapering distribution of the steam breakthrough channel, blocking parameters considering oil drainage radius around the injector, temperature distribution between the injector and the producer and the demand of blocking effect and field reality are obtained to calculate the blocking volume for complete breakthrough wells and incomplete breakthrough wells. This method could be used as a tool to judge breakthrough degree and design profile control parameters for oilfields with heavy oil reservoirs.

Keywords Steam breakthrough channel - Quantitative identification - Profile control design - Heavy oil reservoir . Analytic hierarchy process

\section{Introduction}

Generally, steam flooding is one of the most important thermal recovery methods to develop heavy oil reservoirs. However, after a long period of injecting steam process, steam breakthrough becomes a common problem which seriously influences the development of steam flooding.

The negative effect of steam breakthrough is obvious, such as low heat efficiency, narrow sweep area and high water cut. Thus, foam, polymer and other profile modifying and plugging materials are used to improve steam injection profile and block breakthrough channels (Djabbarah and Weber 1990; Cheng et al. 2004; Wu et al. 2011; Wang et al. 2012a). The design of the volume of profile control agent is based on the volume of the steam breakthrough channel. So the crucial point is that the steam breakthrough should be judged accurately and identified quantitatively. 
It is recognized that there are three typical phenomena of steam breakthrough (Zhang et al. 2002; Cao et al. 2012). The first one is real steam breakthrough. Due to a long time of steam flooding, the injected steam will rapidly advance into production wells through existing high permeability channels and steam even can be seen from the wellbore. The second phenomenon is hot water breakthrough. When steam moves forward to the producers, heat loss will occur and steam will condense into hot water. Then along with the high permeability channel being formed, the hot water will break through into the producers. Sometimes, flash phenomenon can be seen at the wellbore of the producers. The third phenomenon is pressure transmission. When steam is injected and due to pressure transmission, the liquid production rate of the producers nearby elevates and the drawdown pressure of the producer increases, which will easily lead to steam breakthrough or hot water breakthrough if no measures are conducted.

There are many factors leading to steam breakthrough. In summary, steam breakthrough often occurs because of strong heterogeneity of the reservoir, severe steam overlay in thick oil layers, high pressure difference between injector and producer, in-layer thermal/pressure communication, or irrational injection parameters. Many researchers have done a lot of intensive studies. Ge (1982) and Kong et al. (2005) believe that the injected steam will form a globoid with high pressure. The pressure of the globoid will increase along with steam injection. Under certain conditions, the steam under high pressure will break through in the weakest part of the layers. And these layers mainly refer to the areas with the highest permeability. After the breakthrough occurs, the banded steam channel will be formed and it will become the main flow area between the injector and the producer. Yoshiaki (1984) proposed sand deformation theory in the process of steam flooding. He believes that microchannels will be created when steam penetrates the unconsolidated oil sand. The structure of the reservoir will change and the level of pressure and the characteristic of flow will show the difference. Some researchers also declare that most heavy oil reservoir belongs to unconsolidated sandstone (Liu 1998; Yi 2002). So it is easy for sand to move because of low consolidation strength. What is worse, the high pressure and high temperature steam has a great scouring capacity, which aggravates the sand moving out. In addition, heavy oil has a high flow capacity under high temperature. So the drag force of the fluid will overcome the consolidation strength of the rock. Then the skeleton sand will be stripped and breakthrough channeling will be enlarged. What is more, thermal-viscous fingering and steam overlay will also lead to steam penetrating into the producer earlier (Islam and Azaiez 2011; Yuan et al. 2010).
Despite geological and fluidic factors, some engineering factors will also result in steam breakthrough (Ling et al. 1996; Johnson et al. 2004). High steam injection pressure and speed will accelerate reservoir fluid to advance into the producer. Small injector-producer distance will increase the probability of steam breakthrough. In the former steam stimulation process, the production of a producer might not be in synchronization with other nearby producers because of different working system. So called steam breakthrough in steam stimulation may be formed and it will do harm to the following steam flooding. In addition, the high steam stimulation cycle will lead to high water cut around the producer and the increase of heat channels. Then in the following steam flooding, steam breakthrough will easily occur.

At present, the judgment of steam breakthrough is not uniform and the difficulty mainly lies in its various performances. Generally, once steam breakthrough occurs, liquid production rate increases, liquid level rises and water cut increases. These phenomena are not difficult to understand because in steam breakthrough channels, the flow resistance is small and water is the main flow media. When the temperature of the produced hot water exceeds $100{ }^{\circ} \mathrm{C}$, steam which is flashed can be obtained. However, the wellhead temperature of the producer is a controversial factor indicating whether steam breakthrough happens or not. In some cases, high temperature liquid is produced once steam breakthrough occurs. While for others, high temperature liquid is not the necessary condition to demonstrate steam breakthrough happening. This is because the temperature of the producer is sensitive to the variation of liquid production and sometimes the increase of liquid production results from the change of the working system. From Jin 45-31-30 well example in the Liaohe oilfield in China, the temperature of the well bottom keeps at $150{ }^{\circ} \mathrm{C}$ (Zhang 1999). The temperature of the wellbore liquid will increase from 48.64 to $125.55^{\circ} \mathrm{C}$ when the liquid production rate increases from 12 to $84 \mathrm{t} / \mathrm{d}$. Under this condition, even the temperature of the well bottom keeps the same, the temperature of the wellbore will increase rapidly along with the increased liquid production and enlarged drawdown pressure. Furthermore, there are also some cases showing that the temperature may not always increase in the initial stage of steam breakthrough. This is because at the beginning of steam breakthrough, there exists condensate water which is not produced during steam stimulation. When steam breakthrough happens, the condensate water will firstly advance into the producer, which will result in a temperature decrease of the producer. If steam breakthrough further intensifies, the steam or hot water front will arrive at the producer. At this time, the temperature of the liquid production will rapidly increase. 
At present, there are many methods being used to determine breakthrough channels in the process of water flooding, such as injecting tracer material, analyzing well test data, applying fuzzy recognition of expert system based on interpretation results of logging information (Serres-Piole et al. 2012; Liu and Liang 2004; Meng et al. 2007). Some similar technologies have also been used to judge steam breakthrough performance (Closmann 1984; Masse et al. 1991). Generally, the cost of injecting tracer material is expensive and the workload is always heavy. Well test needs to measure pressure changes under the condition of well shut-in, which will influence regular production. For the fuzzy recognition of expert system, its application is always restricted due to non-screening and processing parameters in advance. Recently, $\mathrm{Yu}$ et al. (2009) introduced an integrated discrimination exponent method, which is based on screening and handling geological static parameters, production performance and analytical test data to quantitatively describe breakthrough channels in the water flooding process.

For the judgment of water breakthrough, the most obvious phenomenon is the variation of water production. However, in the steam breakthrough process, except for water cut variation, the temperature of the wellbore is also a significant factor. By introducing steaming time and heat invading volume, Dong and Liu (2012) believes that when the steam front comes to the producer, the temperature of the bottom will suddenly rise and the temperature inflection point symbolizes the start of the steam breakthrough. Through introducing a correlation coefficient, Zheng et al. (2012) declares that if a producer is channeled with several neighboring injectors, the correlation coefficient between the variation of total steam injection of all the injectors and the variation of water production of the producer is greater than the correlation coefficient between the variation of steam injection of each injector and the variation of water production of the producer.

Currently, there are rare studies on quantitative identification of the steam breakthrough channel. Correspondingly to their steam breakthrough identification theories, Dong and Liu (2012) uses heat invading volume to quantitatively describe breakthrough channel. He describes the bottom hole temperature will suddenly increase when the steam arrives at the producer. At that moment, the reservoir pore volume between wells whose temperature is above the bottom hole temperature of the producer is regarded as the heat invading volume. However, the phenomenon of steam breakthrough is not always reflected by the sudden change of temperature. Zheng et al. (2012) establishes an analytic model considering pressure and temperature to calculate breakthrough volume. Based on a non-piston steam displacement model, inter-well formation connection and breakthrough angle, Zhang et al. (2007) calculates the steam sweep volume and screens the optimum blocking volume. Nevertheless, he does not provide an effective method to judge steam breakthrough and only designs agent usage volume depending on totally breakthrough wells.

In this article, a new steam breakthrough identification method based on various static and dynamic data is introduced. Then a new method of optimization of profile control parameters based on the description of mobility variation and temperature distribution in the process of steam breakthrough in heavy oil reservoirs is elaborated. The method has been applied in steam flooding well groups in Henan oilfield in China and achieved good blocking effects.

\section{Physical simulation of steam breakthrough}

Steam breakthrough is affected by many factors, such as permeability contrast, oil viscosity and steam injection parameters. And many field data show that there exist obvious differences between steam breakthrough wells and non-steam breakthrough wells in oil recovery, water cut and temperature. In this paper, the experiments conducted mainly aim to study the characteristics of steam breakthrough under heterogeneous conditions and provide references for the following parameters selection of steam breakthrough identification. Through dual-sandpack physical models with different permeability, the heterogeneity can be obtained and the steam breakthrough channel will be formed in the process of steam injection. Then the variations of temperature and oil recovery between steam breakthrough channel and non-steam breakthrough area can be measured and calculated, which are beneficial to understand the large distinction deduced by steam breakthrough. What is more, the effects of oil viscosity and permeability contrast are discussed.

\section{Experiment apparatus}

The experiment apparatus is shown schematically in Fig. 1 . It mainly contains an injection system, a dual-sandpack model and a liquid metering system. Two ISCO pumps deliver different liquids (steam, water and oil) to the apparatus at a constant volumetric flow rate. High temperature steam is made by a steam generator which can produce a maximum of $350{ }^{\circ} \mathrm{C}$ steam. The sandpack model is $60-\mathrm{cm}$ long with $3.8 \mathrm{~cm}$ inner diameter. Glass beads with different mesh sizes are selected as required. The dualsandpack model, oil tank and water tank are placed in a thermotank to obtain a constant experimental temperature. In order to improve the measurement accuracy, high- 
Fig. 1 Schematic diagram of the experiment apparatus

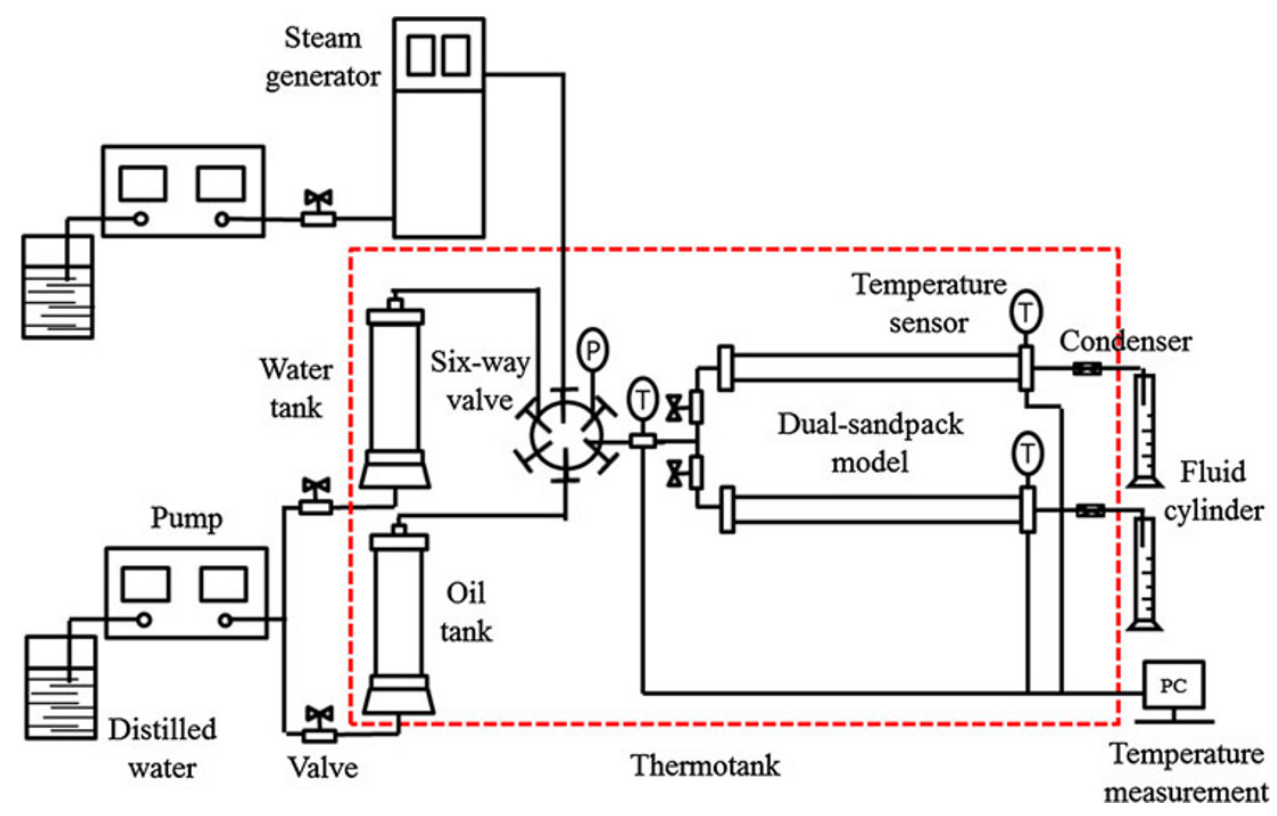

Table 1 Physical parameters of sandpacks

\begin{tabular}{lllllll}
\hline Oil sample & Sand tube number & Length $(\mathrm{cm})$ & Oil viscosity $(\mathrm{mPa} . \mathrm{s})$ & Porosity $(\%)$ & Permeability $\left(10^{-3} \mu \mathrm{m}^{2}\right)$ & Oil saturation $(\%)$ \\
\hline Ordinary heavy oil & 1 & 60 & 6,793 & 41.42 & 4,964 & 92.61 \\
& 2 & 60 & 6,793 & 37.52 & 1,716 & 88.32 \\
& 3 & 60 & 6,793 & 40.91 & 4,871 & 89.21 \\
Extra heavy oil & 5 & 60 & 6,793 & 40.11 & 2,389 & 87.94 \\
& 6 & 60 & 11,300 & 38.86 & 5,872 & 90.92 \\
& 7 & 60 & 11,300 & 34.25 & 1,938 & 87.93 \\
& 8 & 60 & 11,300 & 41.76 & 5,779 & 89.72 \\
\end{tabular}

Table 2 1-9 Scale

\begin{tabular}{cl}
\hline Scale & Implication \\
\hline 1 & A and B are equally important \\
3 & A is a little more important than B \\
5 & A is obviously more important than B \\
7 & A is intensively more important than B \\
9 & A is extremely more important than B \\
$2,4,6,8$, & Median of adjacent judgment above \\
Reciprocal If the ratio of the importance between $i$ and $j$ is $r_{i j}$, then \\
the value between $\mathrm{j}$ and i is $r_{j i}=1 / r_{i j}$
\end{tabular}

precision temperature difference sensors with the measuring range of 0 and $500{ }^{\circ} \mathrm{C}$ are used to measure the inlet and outlet temperatures, whose maximum error is $0.75 \% \mathrm{FS}$ (full scale). They are logged automatically by a personal computer. Besides, in order to prevent high temperature steam flowing out of the sandpack and improve liquid measurement accuracy, condensers are placed at the outlet of each sandpack. The physical parameters of sandpacks and oil viscosities are shown in Table 1.

\section{Experiment procedures}

The properties of sandpacks filled with different mesh sizes of glass beads should be obtained firstly. Before measurement, all apparatuses were connected completely and air tightness of the experiment system must be checked carefully under high pressure (10 MPa) for $1 \mathrm{~h}$. Afterwards, each sandpack was saturated with water at a constant rate and the porosity of each sandpack could be calculated by measuring the difference between the total injection water and total production water. Meanwhile, the permeability could be calculated by the Darcy's law when the water at the outlet flowed steadily and the pressure had no changes. After that, 5 porous volumes $(\mathrm{PV})$ of the oil sample were injected at a constant rate, and the connate water saturation and initial oil saturation were calculated. In the subsequent displacement 
process, high temperature steam with $250{ }^{\circ} \mathrm{C}$ was injected and its injection rate was kept at $2 \mathrm{ml} / \mathrm{min}$. The displacement process would not stop until the water cut of high permeability sandpack reached $98 \%$. Then, each sandpack was refilled with glass bead and repeated the above processes for the next experiment. The injection rate of steam would keep the same and the temperature of the thermotank was kept at $50{ }^{\circ} \mathrm{C}$ during the whole experiment process.

\section{Experiment results}

Figure 2 plots the measured outlet temperature and calculated oil recovery of each sandpack versus the injected porous volume (PV). Because of heat loss in the process of steam injection, the temperature monitored at the outlet of the sandpack is much lower than $250{ }^{\circ} \mathrm{C}$. It is clear that there exists a great temperature difference between the high permeability sand pack and the lower one. The high permeability sandpack is the main flow channel of the steam. So under the influence of high temperature steam, the oil viscosity decreases and its fluidity enhances. Once breakthrough happens, the temperature at the outlet of the high permeability sandpack has a remarkable increase, while the one of low permeability sandpack tends to have no obvious changes and the value is much lower.

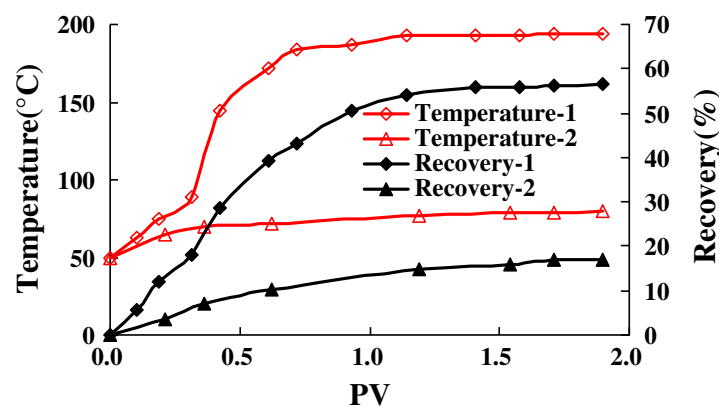

(a) Oil viscosity $=6793 \mathrm{mPa} . \mathrm{s}$, Permeability contrast=2.9

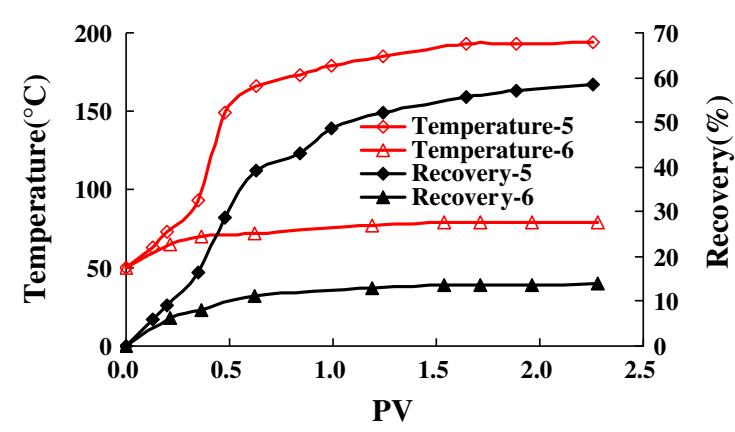

(c) Oil viscosity $=11300 \mathrm{mPa} . \mathrm{s}$, Permeability contrast $=3.0$

Fig. 2 Variation curves between temperature/recovery and the injected porous volume $(\mathrm{PV})$. a Oil viscosity $=6,793 \mathrm{mPa} . \mathrm{s}$, permeability contrast $=2.9$. $\quad$ b Oil $\quad$ viscosity $=6,793 \mathrm{mPa} . \mathrm{s}, \quad$ permeability
Both Figs. 2 and 3 present the large difference of oil recovery between two sandpacks. As shown in Fig. 3, the oil recovery difference between two sandpacks under ordinary heavy oil is about 39.7 and $37.8 \%$. Due to the existence of heterogeneity, the breakthrough channel with small flow resistance in high permeability sandpack restricts steam flowing into the low permeability sandpack, resulting in large residual oil remained and low recovery degree. This phenomenon demonstrates that steam breakthrough has a great negative influence on oil recovery. What is more, compared with ordinary heavy oil, there exists a larger fluidity difference between extra heavy oil and steam. So the oil recovery difference is larger than that of ordinary heavy oil.

It can be also seen that there exists a great positive correlation between temperature and recovery. Nearly most of the oil is produced until the temperature becomes stable. This is an indication of formation of breakthrough channel in the high permeability sandpack. Besides, the permeability contrast, which symbolizes the degree of heterogeneity of the reservoir, has an obvious effect on the steam breakthrough. Even though the permeability contrasts in these experiments are not very large (from 2.0 to 3.0 ), the high permeability sandpack still dominates the flow direction of steam and the phenomenon of steam breakthrough is obvious. Moreover, the results of the

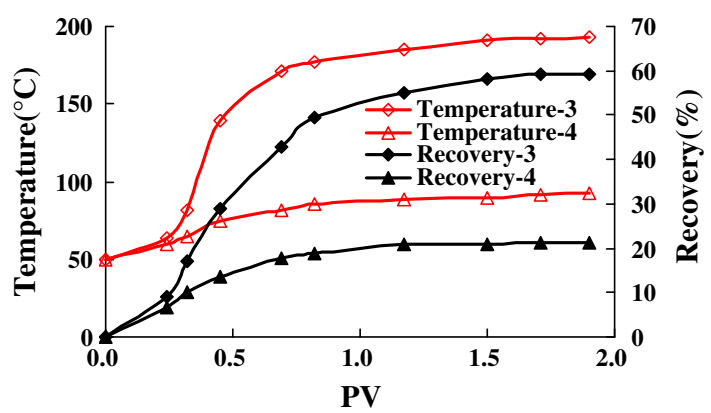

(b) Oil viscosity $=6793 \mathrm{mPa} . \mathrm{s}$, Permeability contrast $=2.0$

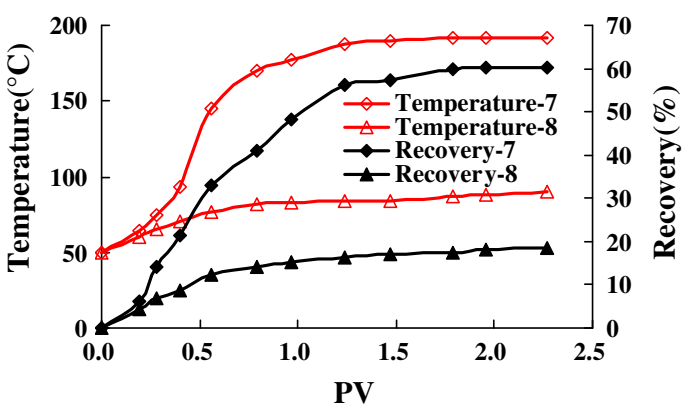

(d) Oil viscosity $=11300 \mathrm{mPa} . \mathrm{s}$, Permeability contrast $=2.2$

contrast $=2.0$. Oil viscosity $=11,300 \mathrm{mPa} . \mathrm{s}$, permeability contrast $=$ 3.0. $\mathbf{d}$ Oil viscosity $=11,300 \mathrm{mPa} . \mathrm{s}$, permeability contrast $=2.2$ 
Fig. 3 Oil recovery comparison. a Permeability contrast $=2.9-3.0$. b Permeability contrast $=2.0-2.2$

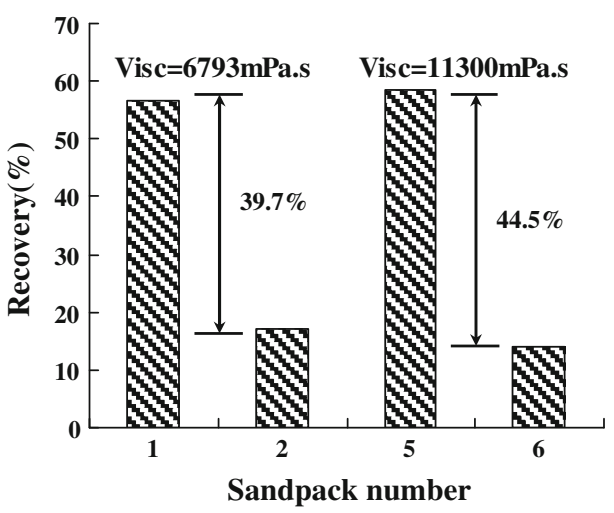

(a) Permeability contrast $=2.9 \sim 3.0$

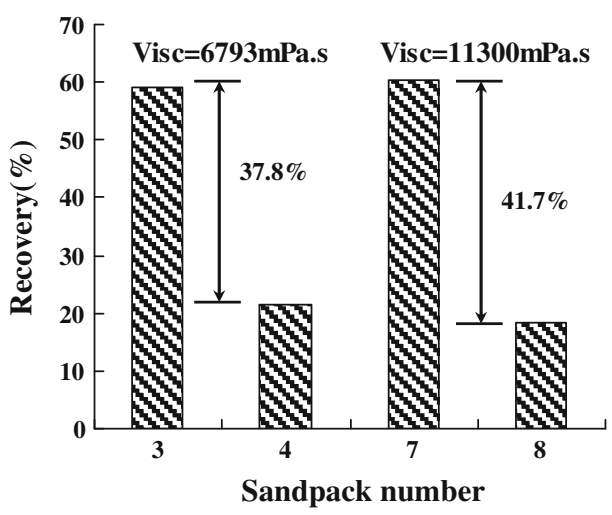

(b) Permeability contrast=2.0 2.2 experiments demonstrate that there occurs a large difference between the breakthrough area and non-breakthrough area in terms of temperature and oil production, and the heterogeneity has a great influence on the occurrence of steam breakthrough. Thus, all of these factors should be considered in the process of identification of steam breakthrough.

\section{Identification of steam breakthrough}

In order to achieve appropriate blocking volume, it is of great importance to identify and calculate steam breakthrough channel. Because the formation of steam breakthrough is mainly influenced by reservoir heterogeneity and operation parameters, both of them should be taken into consideration to identify the breakthrough channel.

\section{Selection of basic parameters}

From the experiment results it can be concluded that permeability is one of the key factors which influence the steam flow direction and the temperature divergence can be treated as an important phenomenon to describe steam injection distinction. So combined with field reality, several basic geology and production parameters are selected as basic parameters, such as permeability, porosity, net pay, injection temperature, production temperature, steam injection volume (cold water equivalent), liquid production rate and oil production rate.

\section{Parameters pretreatment}

All above parameters could reflect the development results and the breakthrough degree of steam flooding from reservoir characters and production situations. However, the focus of each parameter may be different and sometimes it leads to repeatable evaluation or inconsistent evaluation. So it is necessary to pretreat basic parameters.

Through a proper combination of basic parameters, the obtained indexes which are used to evaluate steam breakthrough are as follows:

$R_{1}=\frac{K_{p}}{K_{I}} \quad$ or $\quad R_{1}=\frac{K_{I}}{K_{p}}$

where $R_{1}$ is the permeability contrast between the injector and the producer, $K_{I}$ is the average permeability of the injector and $K_{P}$ is the value of the producer. The larger the $R_{1}$ is, the larger the permeability difference between the injector and the producer is. And steam is much easier to break through along the direction with higher permeability contrast when the permeability is determined at the injector. So in this direction, steam channeling is easily formed.

$R_{2}=\frac{T_{p}}{T_{I}}$

where $R_{2}$ is the temperature difference between the injector and the producer. $T_{I}, T_{P}$ is the wellhead temperature of the injector and the producer. The higher the $T_{P}$ is, the higher the $R_{2}$ is, which indicates the temperature difference between the injection well and the production well is small. It also shows that steam front moves fast in this direction and steam breakthrough may probably occur.

$R_{3}=\frac{N_{w}}{N_{o}}$

where $R_{3}$ is cumulative water-oil ratio of the producer. $N_{w}$, $N_{o}$ is the cumulative water production and cumulative oil production. $R_{3}$ is used to evaluate the water production degree along with oil production. The water produced mainly comes from the injector, so this value can indicate the main injection direction of the steam.

$R_{4}=\frac{q_{l}}{h \phi}$ 
where $R_{4}$ is the fluid producing intensity, $q_{1}$ is the liquid production rate, $h$ is the net pay and $\varphi$ is the porosity of each layer. For multilayer co-production, $q_{l}$ is the total amount of liquid and $h \varphi$ indicates the sum of $h_{1} \varphi_{1}$, $h_{2} \varphi_{2}, \ldots, h_{n} \varphi_{n}$. The fluid producing intensity symbolizes the production capacity of the well. During steam flooding process, the energy of production will mainly come from the injector. So the great intensity of fluid production symbolizes sufficient liquid producing capacity of the producer and it indicates the main flooding direction of the injected steam.

What is more, because the indexes above have different dimension and large distinction of absolute value, then those values are handled by range normalization.

$R_{i}^{\prime}=\frac{R_{i}-R_{\min }}{R_{\max }-R_{\min }}$

where $R_{i}$ ' is the value performed range normalization. For index $i, R_{\max }$ and $R_{\min }$ refer to the maximum value and minimum value.

\section{Comprehensive identification parameter}

In order to consider all indexes above, the comprehensive identification parameter (CIP) is introduced and analytic hierarchy process (AHP) is used to determine the weight of the importance of each index.

AHP, which combines qualitative analysis and quantitative calculation, is regarded as a robust and flexible multicriteria decision-making tool to deal with complex decision problems (Bottero et al. 2011). In the analysis, the complex problem can be divided into several sub-problems which are organized according to hierarchy levels. The top level of the hierarchy denotes the goal of the problem and the intermediate levels denote the factors of the respective upper levels. Once the hierarchy is constructed, pairwise comparison is always conducted to determine the importance of different elements without considering other criteria and alternatives temporarily (Ishizaka and Labib. 2011). Then the results of the comparisons are entered into a matrix and the quantitative judgment matrix is built. Afterwards, through solving the largest eigenvalue and corresponding eigenvectors of the judgment matrix, each level weights of the relative importance of various elements will be determined by the formula below:

$A W=\lambda_{\max } W$

where $A$ is the comparison matrix; $\lambda_{\max }$ is the largest eigenvalue; $W$ is the corresponding eigenvectors indicating weights of each element.

Because the comparison matrix contains redundant information, the AHP model provides a feedback to the decision maker on the consistency of the entered judgments by a measure called consistency ratio (CR) (Saaty 1980):

$C R=\frac{I_{C}}{I_{R}}$

$I_{C}=\frac{\lambda_{\max }-n}{n-1}$

where $I_{C}$ is the consistency index; $n$ is the dimension of the comparison matrix; $I_{R}$ is the ratio index.

$I_{R}$ is the average of the consistency index of 500 randomly generated matrixes. If $\mathrm{CR}$ is higher than 0.1 , it is recommended to revise the comparisons in order to reduce the inconsistency. Once $C R$ is lower than 0.1 , it indicates that the consistency of the matrix is acceptable and the weight of each index is effective.

What' more, it is worth mentioning here that those 4 indexes above all indicate that the larger the value is, the higher the risk of steam breakthrough is. So this criterion is also suitable for CIP.

\section{Identification process of steam breakthrough by using AHP}

In order to decide the weight of permeability contrast $\left(R_{1}\right)$, temperature contrast $\left(R_{2}\right)$, cumulative water-oil ratio $\left(R_{3}\right)$ and fluid producing intensity $\left(R_{4}\right), 1-9$ scale method is used (Saaty 1988, 1994). Its implication is as follows, as shown in Table 2:

Then the comparison matrix $\mathrm{A}$ is obtained and the eigenvector $\mathrm{W}$ and principal eigenvalue $\lambda_{\max }$ can be calculated:

$A=\left\{\begin{array}{llll}a_{11} & a_{12} & a_{13} & a_{14} \\ a_{21} & a_{22} & a_{23} & a_{24} \\ a_{31} & a_{32} & a_{33} & a_{34} \\ a_{41} & a_{42} & a_{43} & a_{44}\end{array}\right.$

$W=\left(w_{1}, w_{2}, w_{3}, w_{4}\right)$

$\lambda_{\max }=\frac{1}{4} \sum_{i=1}^{4} \frac{\sum_{j=1}^{4} a_{i j} w_{i}}{w_{i}}$

where $a_{i j}$ is the comparison scale of every two indexes; $w_{i}$ is the weight of each index.

Through consistency judgment, the weight of each index will be acceptable when $C R$ is lower than 0.1. Then the CIP can be expressed as follows:

$\mathrm{CIP}=\sum_{i=1}^{4} w_{i} R_{i}^{\prime}$

The value of CIP is between 0 and 1 . In order to use CIP to define whether steam breakthrough happens or not, value ranges should be determined. At present, similar 
comprehensive identification parameter is only used to define water breakthrough condition based on the effect of profile control in field application ( $\mathrm{Yu}$ et al. 2009). Through calculating the CIP of wells which successfully conduct profile control and obtain great results, the value range of CIP is defined. Due to breakthrough differentiation of the reality of each oilfield and its expected blocking result, CIP in this article just provides a value range to distinguish steam breakthrough well and incomplete steam breakthrough well. Referring to the classified rules of Gini coefficient (Anna-Bettina and John 2004), CIP below 0.2 suggests no breakthrough, 0.2-0.5 corresponds to a slight breakthrough, over 0.5 suggests a serious breakthrough. Here producers can be generally divided into two types: incomplete breakthrough wells with CIP below 0.5 and complete breakthrough wells with CIP over 0.5 .

\section{Optimization of profile control parameters}

\section{Description basis of steam breakthrough channel}

The description of steam breakthrough channel is the basis of designing profile control. Based on CMG numerical simulation software, the distribution of the water flooding area, steam flooding area and the variation of streamlines are presented. Two 3-D numerical models of $28 \times 28 \times 1$ are set up with the grid size being 2.5, 2.5 and $10 \mathrm{~m}$ in the direction of $I, J$ and $K$, respectively. The displacement is conducted in a homogeneous reservoir model with average permeability, porosity and oil saturation being $2,000 \mathrm{mD}$, 0.3 and 0.7 , respectively. For these two models, all of the reservoir conditions and the injection parameters are the same except for the temperature of the injected water. For water flooding, the temperature of the injected water is $25{ }^{\circ} \mathrm{C}$, and the value is $250{ }^{\circ} \mathrm{C}$ for steam flooding. Figures 4 and 5 show the flow direction of the fluid in each grid and the water saturation distribution of each flooding method when the stable channel is formed. Under this condition, the distribution of water or steam and condensed water become stable and the streamline has few changes. Moreover, the producer has already stepped into the medium and high water cut stage. The dark areas in the figures can approximately symbolize the water flooded area or steam and condensate water area and the red curves reveal the difference of the streamline between water flooding and steam flooding when the water or the steam advances into the producer.

To be specific, during water flooding process, the velocity of water particle on the main streamline is the fastest. Once it advances into the producer, the so called tonguing phenomenon occurs. When stepping into a steady state, the expansion speed of water-flooded area is becoming smaller. And because of little flow resistance in this area, most of the injected water will mainly break through to the producer across this effective water-flooded area. Then a lobate seepage distribution of water will be formed, as shown in Fig. 4.

For heavy oil, its sensitivity of temperature leads to a great fluidity difference under different temperature. In the stage of steam huff and puff, if the interruption of the working system is out of consideration, the sweep area of steam for a producer at the end of steam stimulation is similar to a circle. In this area, the temperature of layers increases obviously and the fluidity of oil is better. So the oil produced almost comes from this area. During the following steam flooding process, the injected steam will invade along with the main streamline between the injector and the producer. And only the oil which is heated by steam can flow effectively. Once steam breakthrough happens, the flow resistance in the steam breakthrough channel decreases very fast. Steam and condensate liquid previously flowing to a variety of directions will rapidly move close to the main streamline and aggregate into the production well. In this case, steam sweep efficiency decreases and the fluidity of heavy oil outside the steam breakthrough channel drops drastically. And most of the produced liquid consists of steam and condensate water. Depending on this theory, the steam breakthrough channel can be divided into two areas: near-wellbore part and interwell part. And with the further development of steam channeling, a taper distribution area of steam and condensed water channel which is different from the lobate

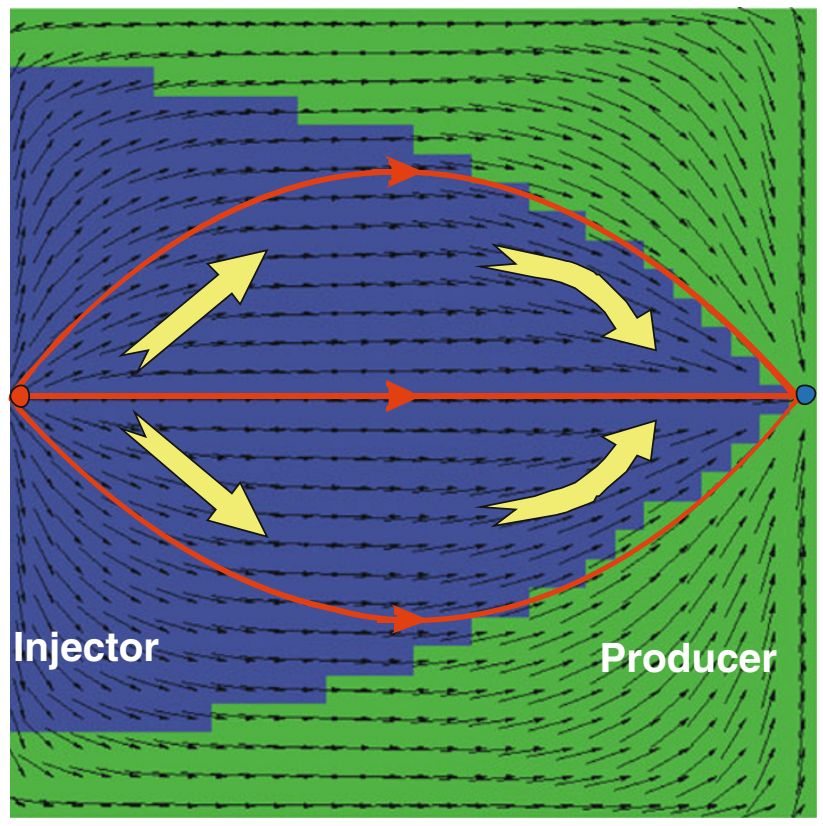

Fig. 4 Lobate distribution of water breakthrough channel 


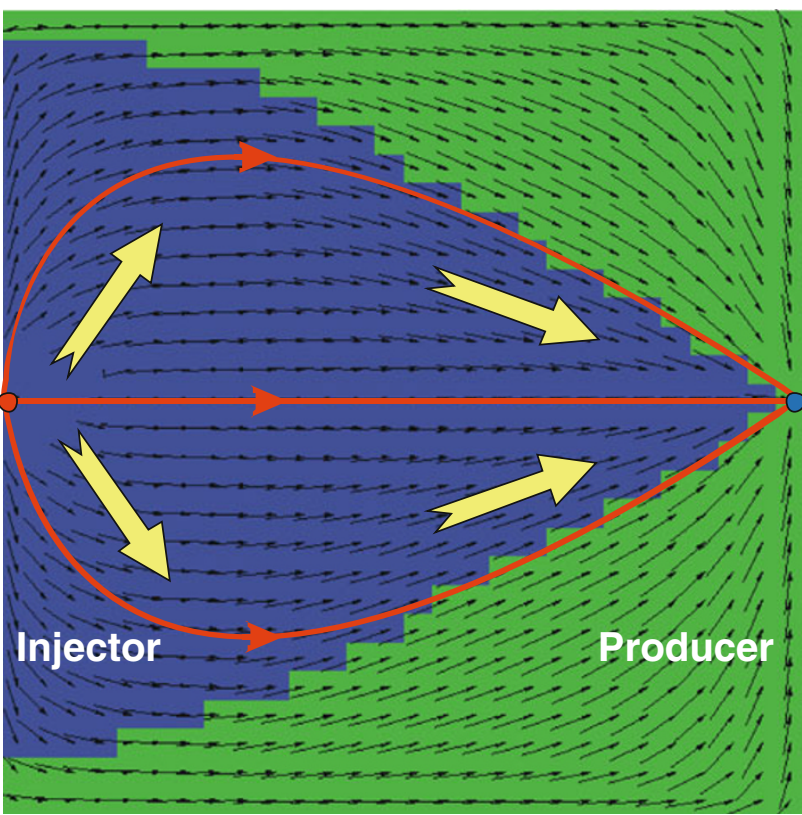

Fig. 5 Tapering distribution of steam breakthrough channel

area in the water flooding process is gradually formed, as shown in Fig. 5.

Determination of blocking area around the injector

According to the above description of steam breakthrough, the calculation of blocking volume is divided into nearwellbore part and interwell part. For the near-wellbore part, the initial blocking radius of the injector depends on the nearby oil deficit volume

$\pi r^{2} h \phi\left(S_{o i}-S_{o c}\right)=N_{p}$

$r=\sqrt{\frac{N_{p}}{\pi h \phi\left(S_{o i}-S_{o c}\right)}}$

where $r$ is the oil drainage radius of the injector at the end of steam stimulation. It is regarded as the initial blocking radius of the steam channel. $N_{P}$ is the cumulative oil production of the injector during steam stimulation process. $h$ is the net pay. $S_{o i}$ is the initial oil saturation and $S_{o c}$ is the residual oil saturation at the end of steam stimulation.

In fact, due to the difference of the working system of nearby producers, $N_{p}$ may not just come from the nearwellbore area. Steam breakthrough may appear in the process of steam stimulation and this phenomenon leads to the heated area near wellbore is not a typical circle (Hunter et al. 1992; Mohammed et al. 2010; Li et al. 2011). But generally, the steam injection time of steam stimulation is short. So the oil drainage area resulting from so called steam flooding during steam stimulation process can be approximately regarded as a circle.
Description of blocking area among injectors and producers

In the process of steam flooding, there always occurs multidirectional steam breakthrough within one well group. So before quantitatively describing the steam breakthrough channel and calculating the blocking volume, the degree of steam breakthrough should be judged. According to the judgment based on CIP and considering the design of blocking volume, all producers are divided into complete steam breakthrough wells and incomplete steam breakthrough wells. Then the calculation of steam breakthrough volume and blocking volume relies on the tapering distribution of the steam breakthrough channel.

Blocking volume for the single-direction complete steam breakthrough well

The channel area of the complete steam breakthrough well in one direction can be simplified as shown in Fig. 6. It consists of oil drainage circle around the injector and the area surrounded by the tangents from the producer to the circle. Then the calculation of the blocking volume can be described as follows:

$V_{C}=S_{C} h_{C} \phi$

$S_{C}=r L \cos \left(\frac{\theta}{2}\right)-(L-R)^{2} \tan \left(\frac{\theta}{2}\right)+\frac{(\pi+\theta)}{2 \pi} \pi r^{2}$

$\theta=2 \arcsin \frac{r}{L}$

where $V_{C}$ is the blocking volume, $\mathrm{m}^{3} ; S_{C}$ is the blocking area of steam breakthrough channel (the shaded area in Fig. 6), $\mathrm{m}^{2} ; h_{C}$ is the average net pay between the injector and the complete breakthrough producer, $\mathrm{m} ; \varphi$ is the average porosity; $r$ is the blocking radius around the injector, $\mathrm{m} ; R$ is the optimum blocking radius, $\mathrm{m} ; L$ is the distance between the injector and the producer, $\mathrm{m} ; \theta$ is the steam breakthrough angle, radian.

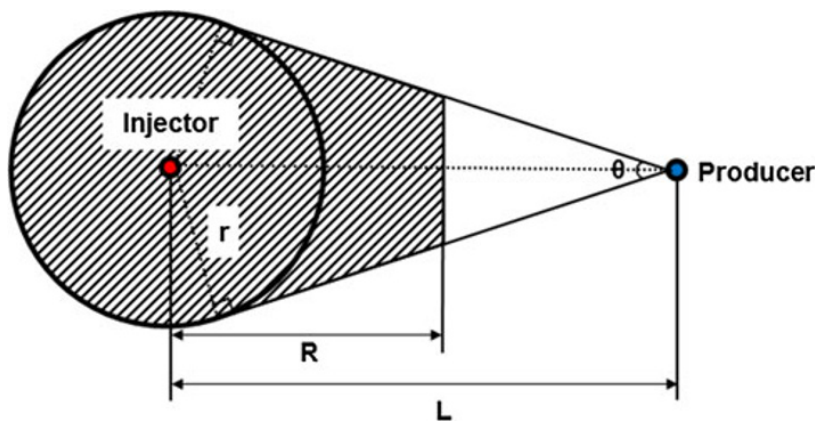

Fig. 6 The area of steam breakthrough channel and blocking area of complete breakthrough well in single direction 
The design of the optimum blocking radius should be based on the validity period of blocking agent. In this article, blocking coefficient $(\gamma)$, which is determined by the demand of blocking effect and field reality, is used to calculate the blocking radius, as described in Eq. (18). Then the optimum blocking radius $(R)$ can be obtained:

$R=\gamma L, \quad \frac{r}{L} \leq \gamma \leq 1$

Blocking volume for the single-direction incomplete steam breakthrough well

For the incomplete steam breakthrough well, the mature breakthrough channel has not been formed. So for some calculating methods of blocking agent volume, this kind of well is not taken into consideration. Such design may not be appropriate because the motion and distribution of the blocking agent among complete breakthrough channels and incomplete breakthrough channels is a dynamic balance process. This phenomenon is especially obvious in the injection process of particle blocking agent (Alvarez et al. 2007; Wang et al. 2012b). So if the blocking volume between the injector and the incomplete steam breakthrough producer is ignored, the designed blocking agent will partly flow to the incomplete breakthrough well. As a result, the designed blocking volume may not be sufficient enough to block the main breakthrough channel and the whole blockage effect will be weakened. In this article, the channel between the injector and incomplete producer is considered.

The channeling volume of incomplete steam breakthrough well in one direction can be simplified as shown in Fig. 7. It consists of oil drainage circle around the injector and the area surrounded by the tangents from the heat intrusion point to the circle. Here the heat intrusion point is used to describe the degree of steam invading between the injector and the incomplete breakthrough producer. Then the blocking volume can be calculated as follows:

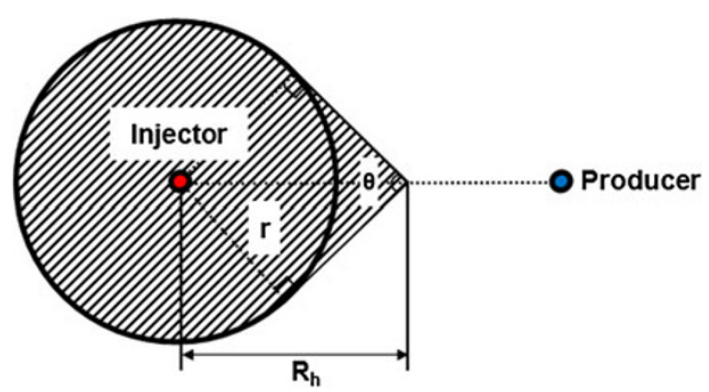

Fig. 7 Blocking area of incomplete breakthrough well in single direction

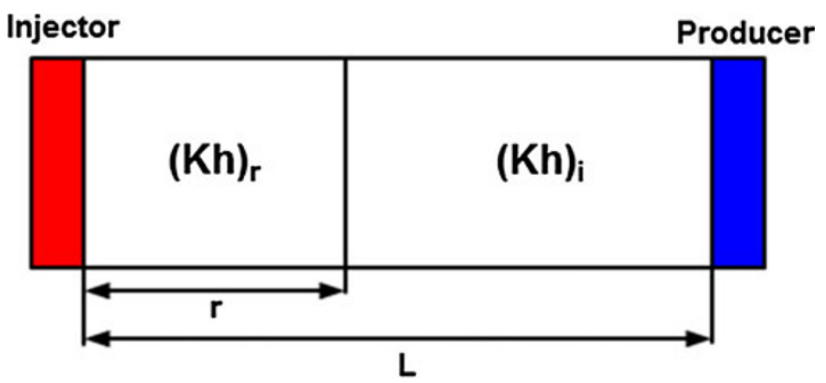

Fig. 8 Heterogeneous model of inter-well formation

$V_{I}=S_{I} h_{I} \phi$

$S_{I}=r R_{h} \cos \left(\frac{\theta}{2}\right)+\frac{\pi+\theta}{2 \pi} \pi r^{2}$

$\theta=2 \arcsin \frac{r}{R_{h}}$

where $V_{I}$ is the blocking volume between the injector and the incomplete breakthrough producer, $\mathrm{m}^{3} ; h_{I}$ is the average net pay between the injector and the incomplete breakthrough producer, $\mathrm{m} ; S_{I}$ is the blocking area, $\mathrm{m}^{2} ; R_{h}$ is the heat intrusion radius, $\mathrm{m} ; \theta$ is the steam breakthrough angle, radian.

Determination of heat intrusion radius

For the incomplete breakthrough well, the heat intrusion radius is regarded as the blocking radius. So in order to obtain the heat intrusion radius, the heat intrusion temperature and the temperature distribution on the main streamline between the injector and the incomplete breakthrough producer should be firstly obtained. Once the temperature distribution is determined, the concrete heat intrusion point can be easily acquired according to the heat intrusion temperature. Then the blocking radius can be achieved. It is well known that steam flooding is a coupled thermal-flow process so a numerical coupling model based on seepage and heat transfer is built to acquire the temperature distribution. The assumptions imposed on heat transfer equations and flow equations include non-isothermal flow, instantaneous local thermodynamic equilibrium, no change of heat transfer parameters, slightly compressible fluids and reservoir rocks, Darcy's law, no physical and chemical change and no hydrocarbon gases.

Firstly, the heat equilibrium equation should be determined. Based on the law of energy conservation, the theory of "Black box analysis" is proposed by Yang et al. (2012) to analyze the process of heat and mass transfer in oil reservoirs. This analysis model ignores the heat transfer between fluid and rock matrix within the system and it just considers the heat transfer between the whole system and the external 
environment. Then corresponding to this theory, the heat equilibrium equation can be expressed as follows:

$$
\begin{gathered}
\nabla\left(\lambda^{*} \nabla T\right)+\nabla\left(\sum_{i=o, w \cdot g} \rho_{i} C_{i} v_{i} T\right)-q_{\text {loss }}+q_{\text {well }} \\
=\frac{\partial}{\partial t}\left[(1-\phi) \rho_{s} C_{s}+\phi\left(\sum_{i=o, w, g} \rho_{i} C_{i} S_{i} T\right)\right]
\end{gathered}
$$

where $\lambda^{*}$ is the thermal conductivity of the equivalent continuous medium; $T$ is the temperature of the reservoir cell at certain time, ${ }^{\circ} \mathrm{C} ; \rho_{s}, \rho_{i=o, w, g}$ is the density of rock, oil, water and steam, respectively, $\mathrm{kg} / \mathrm{m}^{3} . C_{s}, C_{i=o, w, g}$ is the heat capacity of rock, oil, water and steam, respectively, $\mathrm{J} /\left(\mathrm{kJ}{ }^{\circ} \mathrm{C}\right)$.

Depending on representative elementary volume theory (Bear and Bachmat 1990; Al-Raoush and Papadopoulos 2010), the permeable layers are treated as an equivalent continuous medium. Using Latil model, the thermal conductivity of the equivalent continuous medium $\lambda^{*}$ can be described as follows:

$\lambda^{*}=\lambda_{s}^{(1-\phi)}\left(\lambda_{o}+\lambda_{w}+\lambda_{g}\right)^{\phi}$

where $\lambda_{s}$ is the rock thermal conductivity, $\mathrm{J} /\left(\mathrm{m} \mathrm{s}^{\circ} \mathrm{C}\right) ; \lambda_{o}$, $\lambda_{w}, \lambda_{g}$ are the thermal conductivities of oil, water and steam, respectively, $\mathrm{J} /\left(\mathrm{m} \mathrm{s}^{\circ} \mathrm{C}\right) ; \varphi$ is porosity.

Due to assume instantaneous local thermodynamic equilibrium, the Clausius-Clapeyron equation is used:

$p_{g}=p_{g}\left(T_{g}\right)=p_{g}(T)$

where $p_{g}$ is the saturated steam pressure, $0.1 \mathrm{MPa} ; T_{g}$ is the steam temperature under saturated pressure, ${ }^{\circ} \mathrm{C}$.

Assuming thermal conductivity is the only heat exchange method among elementary volume and top and bottom layers, the heat loss can be described as follows:

$q_{\text {loss }}=\left|\nabla\left(\lambda_{c} \nabla T\right)\right|=\left|\rho_{c} C_{c} \frac{\partial T}{\partial t}\right|$

$\rho_{c}$ is the density of top and bottom layers, $C_{c}$ is the heat capacity of top and bottom layers, $\mathrm{J} /\left(\mathrm{kJ}{ }^{\circ} \mathrm{C}\right) ; \lambda_{c}$ is the thermal conductivity of top and bottom layers, $\mathrm{J} /\left(\mathrm{m} \mathrm{s}{ }^{\circ} \mathrm{C}\right)$.

Based on Eqs. (22)-(25), the mathematical model of the temperature field is obtained. For the seepage numerical model, the mass equation can be described as follows:

$\nabla\left[\frac{K K_{r i}}{B_{i} \mu_{i}}\left(\frac{\partial p_{i}}{\partial x}-\rho_{i} g \frac{\partial D}{\partial x}\right)\right]+\mathrm{eq}_{i}=\frac{\partial}{\partial t}\left[\frac{\phi \rho_{i} S_{i}}{B_{i}}\right]$

where $K$ is the absolute permeability, $10^{-3} \mu \mathrm{m}^{2} ; K_{r i}$ is the relative permeability of oil, water and steam, $10^{-3} \mu \mathrm{m}^{2} ; B_{i}$ is the volume coefficient of oil, water and steam; $\mu_{i}$ is the viscosity of oil, water and steam, $\mathrm{mPa}_{\mathrm{s}}$; $\mathrm{eq}_{i}$ is the modified flow rate of the injected or outflowing liquid, $\mathrm{kg} /\left(\mathrm{m}^{3} \mathrm{~s}\right)$; For the injector, e refers to the split coefficient of injection $\left(\varepsilon_{i}\right)$; for the producer, it refers to the split coefficient of production $\left(\eta_{i}\right) . \mathrm{S}_{\mathrm{i}}$ is the saturation of oil, water and steam. Then based on Eqs. (22)-(26), the coupled thermal-flow model is established and the distribution of temperature on the connection between the injector and the producer can be obtained. Once the heat intrusion temperature is determined, the concrete heat intrusion point is obtained through the distribution of temperature, and the heat intrusion radius is achieved. After that, the blocking volume can be calculated based on this radius.

In order to calculate the split coefficient $\varepsilon_{i}$ and $\eta_{i}$, interwell permeability capacity is firstly deduced based on the equivalent flow resistance method (Fig. 8), as shown in Eqs. (27) and (29):

$$
\begin{aligned}
& (\overline{\mathrm{Kh}})_{P i}=\frac{(\mathrm{Kh})_{r}(\mathrm{Kh})_{P i}}{(1-\gamma)(\mathrm{Kh})_{r}+\gamma(\mathrm{Kh})_{P i}} \\
& \varepsilon_{i}=(\overline{\mathrm{Kh}})_{P i} / \sum_{i=1}^{n}(\overline{\mathrm{Kh}})_{P i} \\
& (\overline{\mathrm{Kh}})_{j}=\frac{(\mathrm{Kh})_{r j}(\mathrm{Kh})_{P j}}{(1-\gamma)(\mathrm{Kh})_{r j}+\gamma(\mathrm{Kh})_{P j}} \\
& \eta_{i}=(\overline{\mathrm{Kh}})_{j} / \sum_{i=j}^{n}(\overline{\mathrm{Kh}})_{j}
\end{aligned}
$$

where $(\overline{\mathrm{Kh}})_{P i}$ is the average permeability capacity between the injector and the producer which is in the $i$ direction; $(\mathrm{Kh})_{r}$ is the permeability capacity of the injector and $(\mathrm{Kh})_{P i}$ is the permeability capacity of the producer in the $i$ direction; $(\overline{\mathrm{Kh}})_{j}$ is the average permeability capacity between the producer and the injector which is in the $j$ direction. $(\mathrm{Kh})_{r j}$ is the permeability capacity of the injector in the $j$ direction and $(\mathrm{Kh})_{P j}$ is the permeability capacity in the $\mathrm{j}$ direction of the producer.

For other state equations, such as density $\left(\rho_{i}\right)$, viscosity $\left(\mu_{i}\right)$, porosity $(\varnothing)$ and absolute permeability $(K)$, they can be described as follows (Wang et al. 2012b):

$$
\begin{aligned}
& \rho_{i}=\rho_{0 i}\left[1+C_{V}\left(p_{i}-p_{0}\right)+\alpha_{V}\left(T-T_{0}\right)\right] \\
& \rho_{g}=\rho_{0 g}\left[1+C_{g}\left(p_{g}-p_{0 g}\right)+\alpha_{g}\left(T-T_{0 g}\right)\right] \\
& \lg \mu_{i}=a_{i}-b_{i} T_{0} \\
& \phi=\phi_{0}\left[1+C_{R}\left(p-p_{0}\right)\right] \\
& K=K_{0}\left[1+C_{R}\left(p-p_{0}\right)\right]^{2}
\end{aligned}
$$

where $\rho_{O i}=o, w$ is the density of oil and water when the reference pressure and temperature are $p_{0}$ and $T_{0} \cdot \rho_{0 g}$ is the density of steam when the reference pressure and temperature are $p_{0 g}$ and $T_{0 g} . \rho_{i}=o, w$ is the density of oil and water when the reference pressure and temperature are $p_{i}$ and $T_{i} . \rho_{g}$ is the density of steam when the reference pressure and temperature are $p_{g}$ and $T_{g} . C_{V}$ is the liquid compressibility, $1 / \mathrm{kPa} . \alpha_{V}$ is the coefficient of thermal expansion, $1 /{ }^{\circ} \mathrm{C} . C_{g}$ and $\alpha_{g}$ are the values for steam. $a_{i}$ and $b_{i}$ are the coefficients of the equation of viscosity. $C_{R}$ is the rock compressibility, $1 / \mathrm{kPa}$. 
Let $S_{w}, S_{o}$ and $S_{g}$ be water, oil and steam saturation, respectively. And $p_{w}, p_{o}$ and $p_{g}$ are the water, oil and steam phase pressures, respectively. Then the saturation constraint equation, capillary pressure equation and the relative permeability equation are:

$$
\begin{aligned}
& S_{o}+S_{w}+S_{g}=1 \\
& p_{c g o}=p_{g}-p_{o}, \quad p_{c w o}=p_{o}-p_{w} \\
& K_{r o}=f\left(S_{o}, S_{w}, S_{g}\right), \quad K_{r w}=f\left(S_{o}, S_{w}, S_{g}\right), \\
& \quad K_{r g}=f\left(S_{o}, S_{w}, S_{g}\right)
\end{aligned}
$$

Then, the complete numerical model is established and the temperature distribution between the injector and the producer at any time can be obtained.

Generally, the heat intrusion radius depends on the heat intrusion temperature. And the determination of the heat intrusion temperature can refer to the maximum temperature of the producers and the expected blocking strength. After the heat intrusion temperature is determined, the heat intrusion radius between the injector and the incomplete breakthrough well can be obtained.

Considering the initial oil drainage around the injector, the heat intrusion radius should be compared with the oil drainage radius firstly. Then the blocking area for singledirection incomplete breakthrough well can be acquired as follows:

$S_{I}= \begin{cases}r R_{h} \cos \left(\frac{\theta}{2}\right)+\frac{(\pi+\theta)}{2 \pi} \pi r^{2} & R_{h}>r \\ \pi r^{2} & R_{h} \leq r\end{cases}$

$\theta=2 \arcsin \frac{r}{R_{h}}$

\section{Description of multidirectional breakthrough channel}

For a well group conducting steam flooding, if multidirectional steam breakthrough happens, as shown in Fig. 9, the whole blocking volume consists of multidirectional breakthrough channels. After the breakthrough degree of each producer is defined and the blocking radius of each well is determined, as shown in Fig. 10, then the blocking areas of well $P_{1}\left(R_{1}>r\right), P_{2}$ and $P_{3}$ are calculated as follows:

$S_{I 1}=r R_{1} \cos \left(\frac{\theta_{1}}{2}\right)$

$S_{C 2}=r L_{2} \cos \left(\frac{\theta_{2}}{2}\right)-\left(L_{2}-R_{2}\right)^{2} \tan \left(\frac{\theta_{2}}{2}\right)$

$S_{C 3}=r L_{3} \cos \left(\frac{\theta_{3}}{2}\right)-\left(L_{3}-R_{3}\right)^{2} \tan \left(\frac{\theta_{3}}{2}\right)$

For the overlapping areas, as shown in red shaded areas in Fig. 9:

$S_{O 1}=\frac{1}{2} r^{2} \tan \frac{\alpha_{1}}{2}$

$S_{O 2}=\frac{1}{2} r^{2} \tan \frac{\alpha_{2}}{2}$

$\alpha_{1}=\pi-\frac{\theta_{1}+\theta_{2}}{2}-\theta_{12}$

$\alpha_{2}=\pi-\frac{\theta_{2}+\theta_{3}}{2}-\theta_{23}$

where $\theta_{12}$ and $\theta_{23}$ are angles of the connection between the injector and producers. For the incomplete breakthrough well, if the heat intrusion radius is smaller than the oil
Fig. 9 Blocking diagram of multidirectional steam breakthrough within a well group

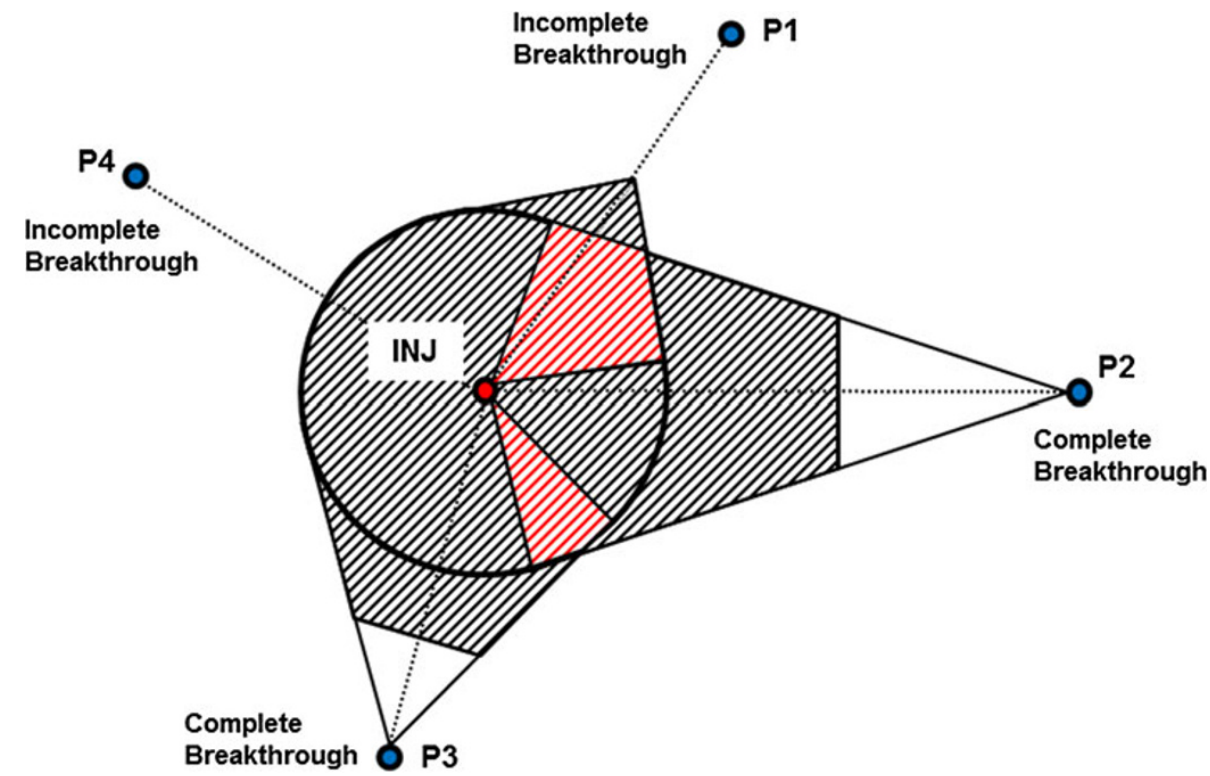


Fig. 10 Blocking volume calculation of multidirectional steam breakthrough within a well group

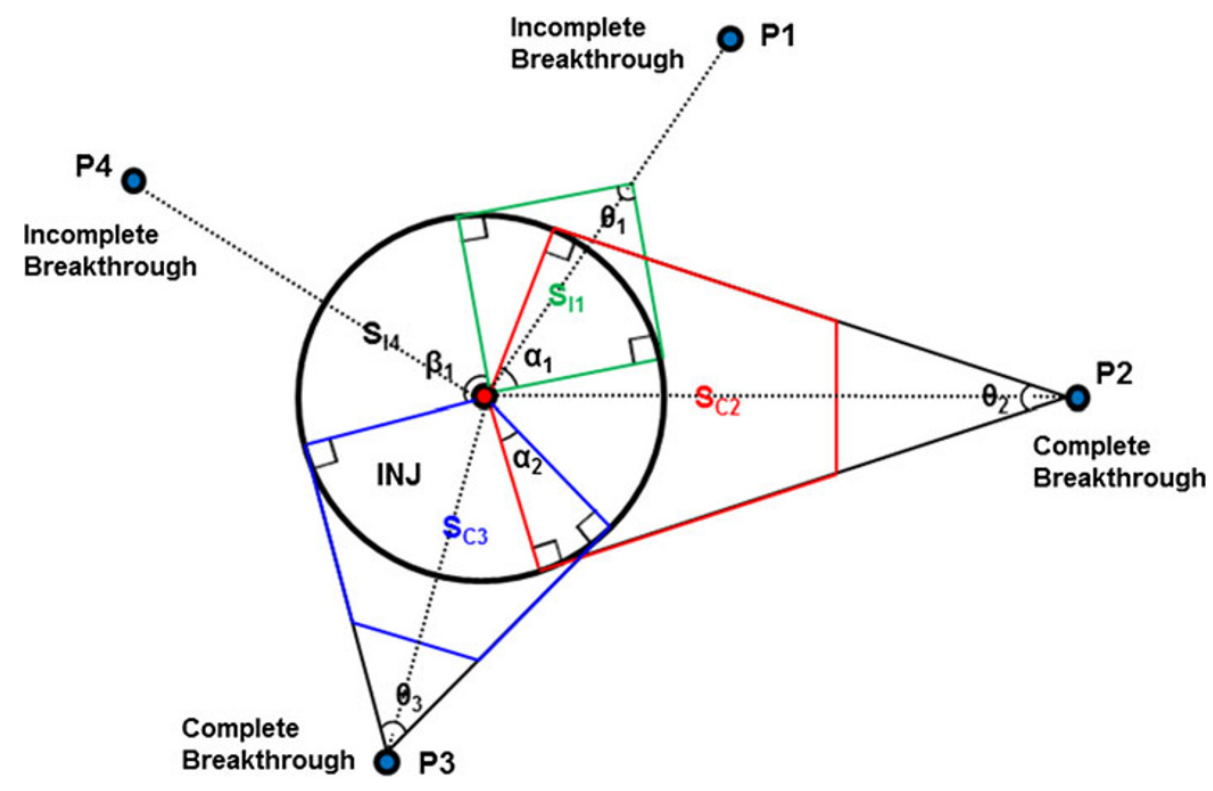

drainage radius, taking $P_{4}$ as an example. Then, the blocking area in this direction is as follows:

$$
\begin{aligned}
S_{I 4} & =\frac{\beta_{1}}{2 \pi} \pi r^{2}, \beta_{1} \\
& =2 \pi-\left[\left(\pi-\theta_{1}\right)+\left(\pi-\theta_{2}\right)+\left(\pi-\theta_{3}\right)-\alpha_{1}-\alpha_{2}\right]
\end{aligned}
$$

Then based on the average net pay of the well group $(\bar{h})$ and the average porosity $(\varphi)$, the whole blocking volume can be calculated as follows:

$$
\begin{aligned}
& V_{\text {total }}=S_{\text {total }} \bar{h} \phi \\
& S_{\text {total }}=S_{I 1}+S_{C 2}+S_{C 3}+S_{I 4}-S_{O 1}-S_{O 2}
\end{aligned}
$$

In summary, the process of calculating the whole blocking volume within one steam flooding well group where multidirectional breakthrough happens is as follows:

1. Use the AHP method and CIP criterion in the article to define the steam breakthrough types of all producers: complete breakthrough wells $1,2, \ldots, n$; incomplete breakthrough wells $1,2, \ldots, m$;

2. For complete breakthrough wells, $\gamma_{i}$ is used to determine blocking radius and the blocking areas $S_{C 1}, S_{C 2}, \ldots, S_{C n}$ are calculated as: $S_{C i}=r L_{i} \cos \left(\frac{\theta_{i}}{2}\right)-$ $\left(L_{i}-R_{i}\right)^{2} \tan \left(\frac{\theta_{i}}{2}\right)$

3. For incomplete breakthrough wells, after comparison between heat intrusion radius and oil drainage radius, the blocking areas $S_{I 1}, S_{I 2}, \ldots, S_{I m}$ are calculated as:

$$
S_{I j}= \begin{cases}r R_{h j} \cos \left(\frac{\theta_{j}}{2}\right) & R_{h j}>r \\ \frac{\beta_{j}}{2 \pi} \pi r^{2} & R_{h j} \leq r\end{cases}
$$

4. Calculate overlapping blocking areas $S_{O 1}, S_{O 2}, \ldots$

5. Obtain the whole blocking volume: $V_{\text {total }}=\left(\sum_{i=1}^{n} S_{C i}\right.$ $\left.+\sum_{j=1}^{m} S_{I j}-\sum S_{O k}\right) \bar{h} \phi$

\section{Field application}

XQ45 block in Henan Oilfield in China is a typical shallow-thin-layer heavy oil reservoir. The buried depth of the reservoir is $75-245 \mathrm{~m}$ and the average temperature is $26{ }^{\circ} \mathrm{C}$. The oil sample is obtained from the oilfield and the viscosity of the gas-free oil is measured by water bath heating under the laboratory condition. The viscositytemperature curve is shown in Fig. 11.

After a few months of steam flooding, steam breakthrough was becoming a serious problem which played a detrimental effect on the improvement of thermal recovery.

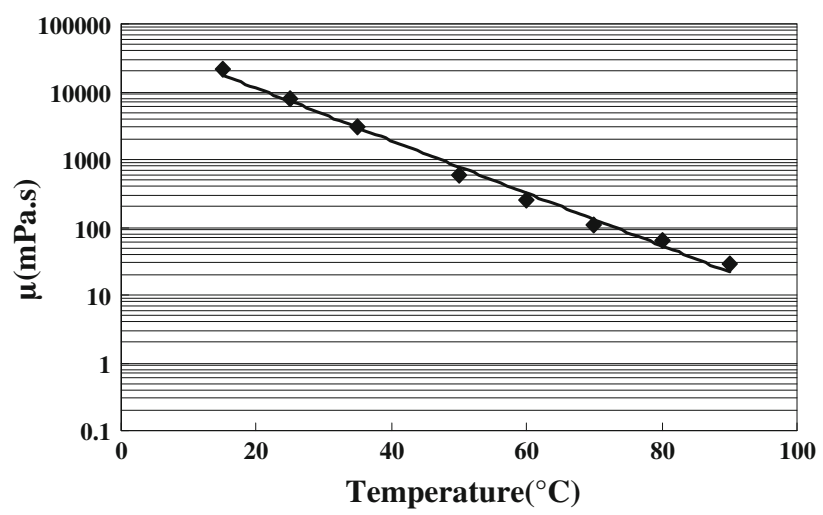

Fig. 11 The viscosity-temperature curve of the oil sample (gas-free) 
Then, well groups X4101, X4403, X4611 were firstly selected to use nitrogen foam to improve the profile. The calculation of the blocking volume of the nitrogen foam was based on the method of this article.

\section{Identification of breakthrough degree}

For well group X4403, the production data by 1 September, 2011 are shown in Table 3. Then based on Eqs. (1)-(5), range normalization is conducted. After that, according to AHP and 1-9 scale method, eigenvector and principal eigenvalue are calculated and the CIP of each producer is obtained after consistency judgment. Table 4 shows the pairwise comparison of 4 indexes and Table 5 shows a concrete comparison of the evaluation parameters of each producer in well group X4403.

It can be seen from Table 5 that the CIP of X4303, X44021 and X4404 all exceeds 0.5. Depending on the judging criteria, these three wells are complete breakthrough wells. To be specific, the largest value of CIP of $\mathrm{X} 4303$ is attributed to the high temperature of the production liquid, high cumulative water-oil ratio and high water cut, which constitute typical phenomena of complete breakthrough. For X44021 and X4404, the fluid producing intensity and cumulative water-oil ratio are both very high and the water cut reaches 0.95 , even though the temperature of the well does not increase that much. These values indicate these two wells also show obvious breakthrough phenomena and these characteristics are well reflected on CIP. For incomplete wells, because steam breakthrough is a comprehensive reflection of various influencing factors, so the high value of certain factor may not definitely indicate a serious breakthrough. Just like X4503, the water cut reaches 0.92 while the temperature of the production liquid is just $39^{\circ} \mathrm{C}$ and the fluid producing intensity is low. So these might indicate this well has not totally stepped into complete breakthrough stage. Correspondingly, the

Table 3 Basic information of well group X4403

\begin{tabular}{|c|c|c|c|c|c|c|c|}
\hline & $\begin{array}{l}\text { Well } \\
\text { name }\end{array}$ & $\begin{array}{l}\text { Permeability } \\
\left(\mu \mathrm{m}^{2}\right)\end{array}$ & Net pay (m) & $\begin{array}{l}\text { Temperature } \\
\left({ }^{\circ} \mathrm{C}\right)\end{array}$ & $\begin{array}{l}\text { Liquid production rate } \\
(\mathrm{t} / \mathrm{d})\end{array}$ & $\begin{array}{l}\text { Cumulative water } \\
(t)\end{array}$ & $\begin{array}{l}\text { Cumulative oil } \\
(t)\end{array}$ \\
\hline Injector & X4403 & 1.10 & 9.15 & 223 & - & - & - \\
\hline \multirow[t]{7}{*}{ Producer } & X43011 & 1.94 & 10.27 & 41 & 14.1 & $1,948.5$ & 316.4 \\
\hline & X4302 & 1.60 & 9.6 & 52 & 28.2 & $5,167.8$ & 333.6 \\
\hline & X4303 & 1.50 & 13.6 & 98 & 19.5 & $3,173.3$ & 160.7 \\
\hline & X44021 & 1.90 & 10.01 & 59 & 26.0 & 5,421 & 329.4 \\
\hline & X4404 & 1.88 & 5.42 & 55 & 13.0 & $3,411.9$ & 136.4 \\
\hline & X4503 & 1.20 & 8.4 & 39 & 5.4 & $3,200.8$ & 263.2 \\
\hline & X4504 & 0.81 & 5.6 & 68 & 19.5 & $3,586.7$ & 934.2 \\
\hline
\end{tabular}

Table 4 Pairwise comparison of 4 indexes

\begin{tabular}{lllll}
\hline & $R_{1}$ & $R_{2}$ & $R_{3}$ & $R_{4}$ \\
\hline$R_{1}$ & 1 & $1 / 3$ & $1 / 3$ & 2 \\
$R_{2}$ & 3 & 1 & 1 & 3 \\
$R_{3}$ & 3 & 1 & 1 & 3 \\
$R_{4}$ & $1 / 2$ & $1 / 3$ & $1 / 3$ & 1 \\
\hline
\end{tabular}

Table 5 Comparison of evaluation parameters of each producer

\begin{tabular}{lllllll}
\hline Breakthrough type & Well name & CIP & Temperature $\left({ }^{\circ} \mathrm{C}\right)$ & Water cut & Cumulative water-oil ratio & Fluid producing intensity (t/(d.m)) \\
\hline Complete & X4303 & 0.7718 & 98 & 0.9518 & 19.75 & 5.54 \\
& X44021 & 0.5661 & 59 & 0.9427 & 16.46 & 9.91 \\
Incomplete & X4404 & 0.6818 & 55 & 0.9616 & 25.01 & 9.26 \\
& X43011 & 0.2326 & 41 & 0.8603 & 6.16 & 5.32 \\
& X4302 & 0.4795 & 52 & 0.9394 & 15.49 & 11.34 \\
& X4503 & 0.1978 & 39 & 0.9240 & 12.16 & 2.50 \\
\hline
\end{tabular}


CIP of this well is below 0.5 . In addition, it can be seen that the water cut, cumulative water-oil ratio and fluid producing intensity of X4302 also stay at a relatively high level. Based on the CIP judgment in the paper, this well is regarded as an incomplete breakthrough well. But it is worth noting that the CIP of X4302 is so close to 0.5. This indicates that although this well is currently treated as an incomplete breakthrough well, it may soon turn into a complete breakthrough well if no measures are conducted. And this judgment is consistent with the actual situation of the producer. What is more, it can be seen that the X43011 and X4504 are both treated as incomplete breakthrough wells and the CIP of them are similar. However, there exist obvious differences in concrete evaluation parameters. The temperature of production liquid and the fluid producing intensity of X43011 are lower than those of X4504. However, the water cut of X43011 is higher and the cumulative water-oil ratio is nearly twice as large as the value of $\mathrm{X} 4504$. So it might be not easy to judge which well occurring more serious breakthrough, and the degree of breakthrough of these two wells might be similar. The CIP of these wells can just reflect this similarity.

It is worth mentioning here that, the weight of temperature and cumulative water-oil ratio in this article are the largest for calculating CIP. These two factors are always regarded as the most important parameters to judge the degree of steam breakthrough. Cumulative water-oil ratio is also an important factor reflecting water cut. Based on above discussions, some recognitions could be achieved: for wells with high water cut and high temperature of the production liquid simultaneously, they have a high CIP value which exceeds 0.5 and they can be regarded as complete breakthrough wells; for wells with high water cut and low temperature of the production liquid, a hot water breakthrough might occur but probably with low degree of breakthrough. So the CIP values of these wells might be lower than 0.5 and they can be regarded as incomplete breakthrough wells; for wells with low water cut and high temperature, the degree of breakthrough may also be low and the CIP value is lower than 0.5 , so these wells are also regarded as incomplete breakthrough wells; for wells with low water cut and low temperature, no breakthrough happens.

\section{Calculation of breakthrough channel volume}

Figure 12 shows temperature profiles for the producers of well group X4403. As above description, X4303, X44021 and X4404 are complete breakthrough wells and the other four wells belong to incomplete breakthrough well. It can be seen that for incomplete breakthrough wells with long injection-production distance and low fluid producing intensity, such as X43011 and X4503, the temperature of the producing liquid is low and long distance around the producers have not been heated yet. For other two incomplete breakthrough wells, X4302 and X4504, due to relatively short injection-production distance and high fluid producing intensity, the wellhead temperature has increased and relatively long distance close to the injector has been effectively heated. For the complete breakthrough wells, such as X4303, most of the injection-production distance shows high temperature, which indicates the major part of the interwell has been affected by the high temperature steam. Nevertheless, the temperature distributions of X44021 and X4404 do not show obvious differences compared with those of the incomplete breakthrough wells. This phenomenon also indicates that the temperature is just one of the factors indicating steam breakthrough.

In order to calculate blocking volumes, the oil drainage radius of the injector should be firstly obtained. According to the production data and based on Eq. (14), the oil drainage radius of the injector X4403 is $14.32 \mathrm{~m}$. For the incomplete breakthrough wells, X43011, X4302, X4503 and $\mathrm{X} 4504$, the heat intrusion temperature of the well group is determined by the maximum temperature of all of the complete breakthrough wells and heat intrusion radiuses are obtained from the temperature profiles, as shown in Fig. 12. For the well group of X4403, the heat intrusion temperature is set at $98^{\circ} \mathrm{C}$ and average net pay and porosity are $8 \mathrm{~m}$ and 0.26 , respectively. In summary, the blocking parameters and blocking agent volume of well group X4403 are shown in Table 6. Using the same method, the blocking agent volumes of well groups X4101 and $\mathrm{X} 4611$ are 2,528.79 and $4,197.45 \mathrm{~m}^{3}$. In addition, Fig. 13 shows the comparisons between the calculated breakthrough channel volumes and the numerical simulation results of steam and condensed water saturation of each producer for those three well groups. It can be seen

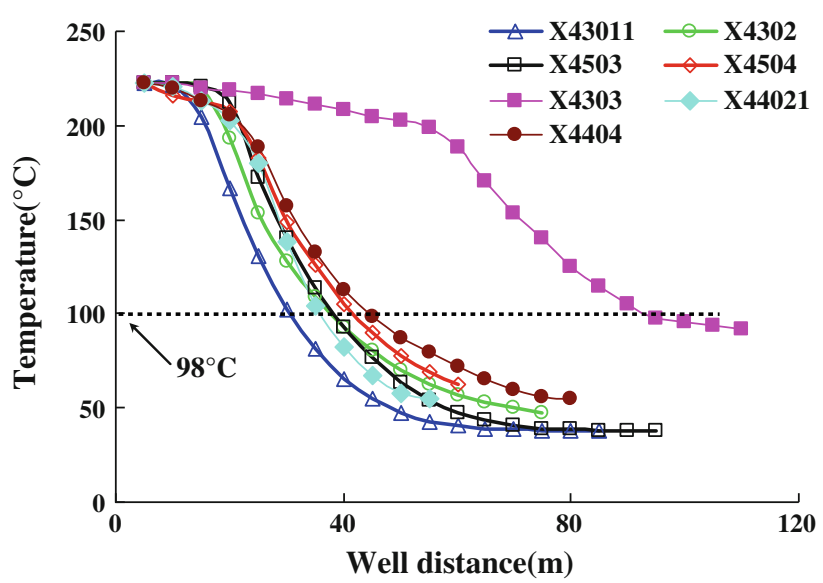

Fig. 12 Variation curves between temperature and well distance on 1 September, 2011 
Table 6 Blocking parameters and agent usage volume of well group X4403

\begin{tabular}{|c|c|c|c|c|c|}
\hline Well name & Blocking coefficient & Blocking radius $(\mathrm{m})$ & Blocking area $\left(\mathrm{m}^{2}\right)$ & $\begin{array}{l}\text { Ultimate blocking } \\
\text { area }\left(\mathrm{m}^{2}\right)\end{array}$ & $\begin{array}{l}\text { Blocking agent } \\
\text { volume }\left(\mathrm{m}^{3}\right)\end{array}$ \\
\hline X4303 & 0.3 & 33.01 & 783.50 & $1,559.06$ & $3,242.84$ \\
\hline X44021 & 0.3 & 16.40 & 358.07 & & \\
\hline X4404 & 0.3 & 23.94 & 554.99 & & \\
\hline X43011 & - & 31.00 & 286.56 & & \\
\hline X4302 & - & 36.36 & 478.59 & & \\
\hline $\mathrm{X} 4503$ & - & 37.75 & 500.18 & & \\
\hline X4504 & - & 41.28 & 554.42 & & \\
\hline
\end{tabular}

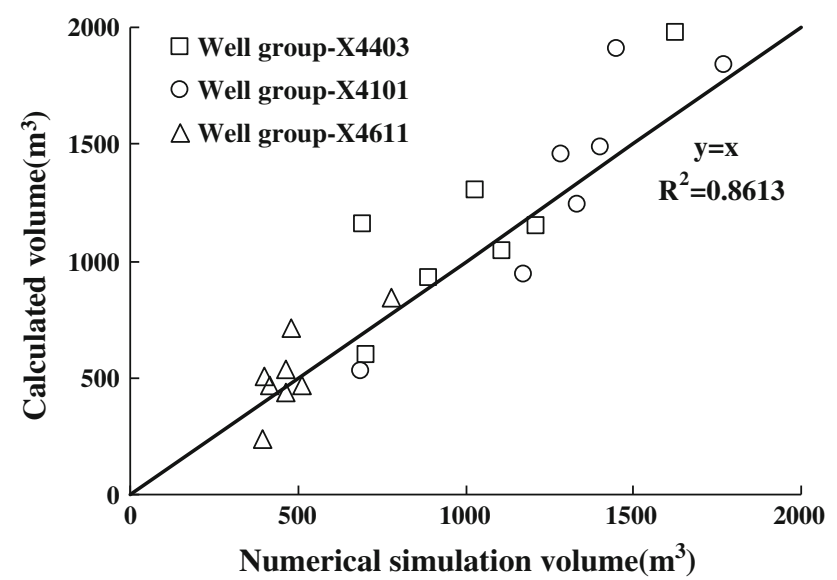

Fig. 13 Comparison between the calculated breakthrough channel volume and the numerical simulation results

that most of the calculated breakthrough channel volumes have a good consistency with the numerical simulation results of the steam and condensate water volume. It indicates that the calculated method in this paper could approximately reflect the volume of the steam and condensate water, which plays an important role in designing the volume of the blocking agent.

Moreover, in the statistical process, we find the calculated breakthrough volumes of the complete breakthrough well tend to be larger than those of the numerical simulation results. However, the calculated volumes of the incomplete breakthrough well are more likely to be smaller than those of the numerical simulation results. This phenomenon might result from the difference of the calculation methods. For the complete breakthrough well, due to the steam override, the variety of the steam and condensate water profiles of different layers is large. For the calculation method of the complete breakthrough well, the steam override is not taken into consideration. For the incomplete breakthrough well, the breakthrough radius is smaller than the well spacing, and this may lead to the calculated breakthrough area being smaller than the real steam and

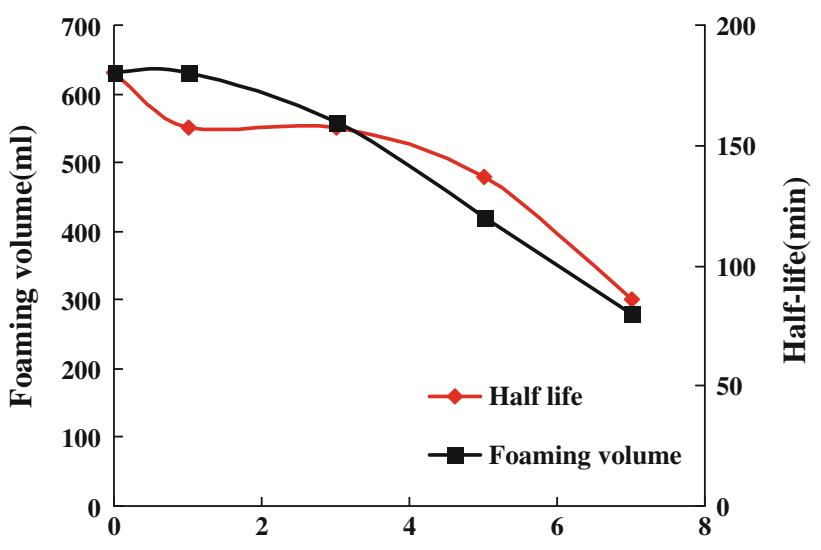

High temperature duration time(day)

Fig. 14 Foaming volume and half-life of the foaming agent under different high temperature duration time

condensate water area. In summary, the precise relation between the calculated breakthrough volume and the numerical simulation results for complete breakthrough wells and incomplete breakthrough wells needs further study.

\section{Application results}

Before the profile control, the foaming agent was firstly screened and the properties as well as the injection parameters of the foam were measured and optimized under the experimental condition. The optimum foaming agent was a kind of anionic surfactants and some properties are shown in Figs. 14 and 15. Figure 14 plots the foaming volume and half-life of the foaming agent with different duration time under the high temperature $\left(250^{\circ} \mathrm{C}\right)$. Figure 15 shows the resistance factors of the original foaming agent under different temperatures and the values of the foaming agent which conducts high temperature degradation. These testing results show that although the high temperature has a negative influence on the foaming 


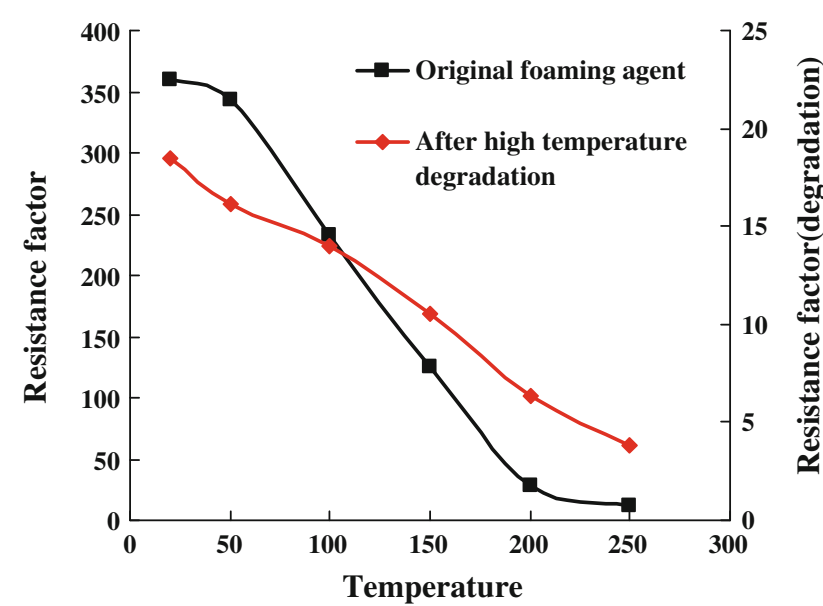

Fig. 15 Resistance factors of the original foaming agent and the high-temperature-degradation sample $\left(7\right.$ days under $\left.250{ }^{\circ} \mathrm{C}\right)$ under different temperatures

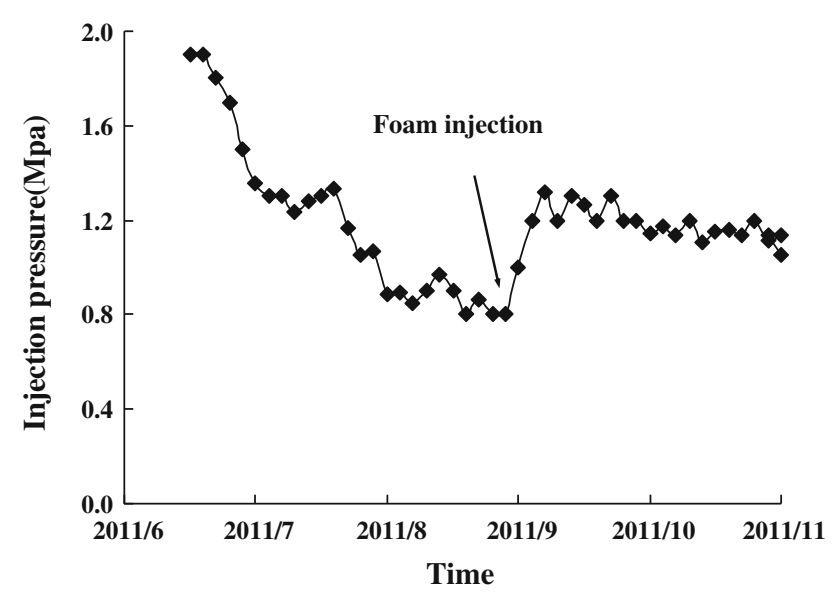

Fig. 16 Pressure curve of X4101

volume, half-life and blocking capacity, this foaming agent still presents relatively strong stability under high temperature. For the field application, the optimum concentration of the foaming solution and gas-liquid ratio was $0.5 \mathrm{wt} \%$ and $2 / 1$, respectively.

Profile control for well group X4101 was conducted on 3 September, 2011 and the real foam injection volume is $2,516 \mathrm{~m}^{3}$. Wellhead pressure of X4101 during steam and foam injection process is shown in Fig. 16. On the 3 day of steam and foam injection, the wellhead pressure increased from 0.80 to $1.32 \mathrm{MPa}$. The profile control for well groups X4403 and X4611 were conducted on 4 September, 2011, and the foam injection volume of each well group was 3,170 and $3,996 \mathrm{~m}^{3}$. Wellhead pressures of these two injectors are shown in Figs. 17 and 18. The wellhead pressure of X4403 increased from 0.71 to $1.22 \mathrm{MPa}$ within 5 days and the wellhead pressure of X4611 also increased

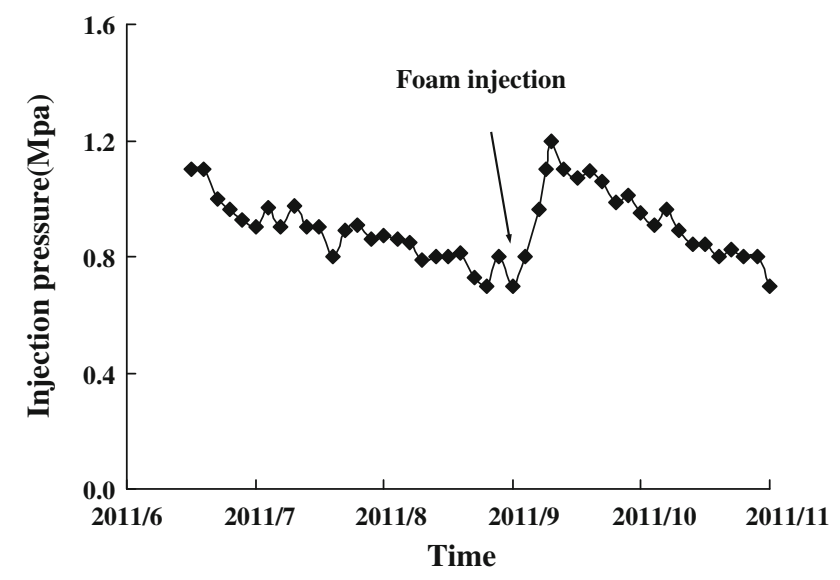

Fig. 17 Pressure curve of X4403

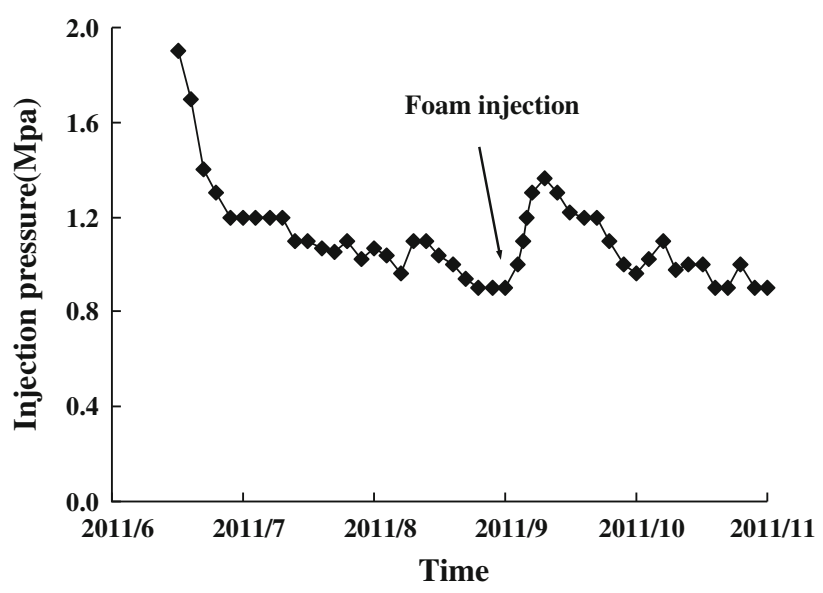

Fig. 18 Pressure curve of X4502

from 0.90 to $1.36 \mathrm{MPa}$ within the same time. So the increase of wellhead pressure indicated blocking by foam in steam channels in the formation. These results showed that the design method introduced in this article was useful and the calculation of the blocking volume of steam breakthrough channeling was beneficial for the field application.

\section{Conclusions}

1. Dual sandpack experiments results show that permeability contrast is an important factor controling the steam flow direction. And there exists a great positive correlation between temperature and oil recovery. Once steam breakthrough occurs, the temperature of the high permeability area stays at a high level and the 
temperature and oil recovery distinction between steam channel and unheated area is large.

2. Based on geological parameters and field production data, as well as through a series of parameters pretreatment and combination, CIP is achieved to quantitatively describe the degree of steam breakthrough. The larger the CIP is, the more serious the steam breakthrough is. All producers can be divided into complete steam breakthrough wells with CIP below 0.5 and incomplete breakthrough wells with CIP over 0.5 . And considering the migration and distribution of plugging agent in the formation, incomplete breakthrough wells need to be considered during profile control design.

3. According to the fluidity variation before and after steam breakthrough, a tapering distribution of steam breakthrough channel in heavy oil reservoirs is described. And based on this description, the steam breakthrough volume and blocking volume for single direction complete breakthrough well, single direction incomplete breakthrough well and multidirectional breakthrough wells within one well group are calculated.

4. The identification and calculation method in this article was applied to induct profile control in the process of steam flooding in Henan oilfield in China. The rapid increase of injection pressure indicates good blocking result in steam channels in the formation. It also proves this method could be used as a tool to judge breakthrough degree and design profile control parameters for oilfields with heavy oil reservoirs.

Acknowledgments This work was financially supported by the National Natural Science Foundation of China (51104165) and the National Science and Technology Major Project of China (2011ZX05009-004-05). The authors also wish to appreciate the Key Laboratory of Petroleum Engineering of the Ministry of Education, China University of Petroleum for the permission to publish this paper.

Open Access This article is distributed under the terms of the Creative Commons Attribution License which permits any use, distribution, and reproduction in any medium, provided the original author(s) and the source are credited.

\section{References}

Al-Raoush R, Papadopoulos A (2010) Representative elementary volume analysis of porous media using X-ray computed tomography. Powder Technol 200(1-2):69-77

Alvarez AC, Hime G, Marchesin D et al (2007) The inverse problem of determining the filtration function and permeability reduction in flow of water with particles in porous media. Transp Porous Med 70:43-62
Anna-Bettina H, John PAI (2004) The Gini coefficient as a measure for understanding accrual inequalities in multicenter clinical studies. J Clin Epidemiol 57(4):341-348

Bear J, Bachmat Y (1990) Introduction to modeling of transport phenomena in porous media, Kluwer

Bottero M, Comino E, Riggio V (2011) Application of the analytic hierarchy process and the analytic network process for the assessment of different wastewater treatment systems. Environ Model Softw 26(10):1211-1224

Cao YB, Liu DQ, Zhang ZP et al (2012) Steam channeling control in the steam flooding of super heavy oil reservoirs, Shengli Oilfield. Petrol Exp Dev 39(6):739-743

Cheng LS, Liang L, Lang ZX et al (2004) Mechanistic simulation studies on the steam-foam drive in superviscous oil reservoirs. J Petrol Sci Eng 41(1-3):199-212

Closmann PJ (1984) Steam zone growth in cylindrical channels. SPE J 24(5):481-484

Djabbarah NF, Weber SL, Freeman DC et al (1990) Laboratory design and field demonstration of steam diversion with foam. In: Paper 20067-MS presented at the SPE California Regional Meeting, California

Dong XH, Liu HQ (2012) Investigation of the features about steam breakthrough in heavy oil reservoirs during steam injection. Open Petrol Eng J 5(1):1-6

Ge JL (1982) Reservoir fluid mechanism. Petroleum Industry Press, Beijing, pp 105-120

Hunter BL, Buell RS, Abate TA (1992) Application of a polymer gel system to control steam breakthrough and channeling. In: Paper 24031-MS presented at the SPE Western Regional Meeting, California

Ishizaka A, Labib A (2011) Selection of new production facilities with the group analytic hierarchy process ordering method. Expert Syst Appl 38(6):7317-7325

Islam MN, Azaiez J (2011) Thermo-viscous fingering in quarter fivespot miscible displacements. Eur J Mech B/Fluids 30(1):107-119

Johnson D, Sugianto OR, Mock PH et al (2004) Identification of steam-breakthrough intervals with DTS technology. SPE Prod Facil 19(1):41-48

Kong XY, Li DL, Xu XZ et al (2005) Study on the mathematical models of coupled thermal-hydrological-mechanical (THM) processes. J Hydrodyn 20(2):269-275

Li SY, Li ZM, Li BF (2011) Experimental study and application on profile control using high-temperature foam. J Petrol Sci Eng 78(3-4):567-574

Ling JJ, Song ZY, Wang Y et al (1996) A study of the essentials of steam channeling in the process of steam soaking. J Jianghan Petrol Inst 18(1):58-61

Liu WZ (1998) The development models of heavy oil reservoirs by thermal recovery. Petroleum Industry Press, Beijing, pp 306-317

Liu SF, Liang JD (2004) Discussion for an approach to specifying injection and recovery cyclic channel by well testing technology. Well Test 13(1):27-30

Masse PJ, Geosney TC, Long DL (1991) Use of pulsed-neutron capture logs to identify steam breakthrough-case study: South Belridge middle expansion steam flood Project. SPE Form Eval 6(3):319-326

Meng FS, Sun TJ, Zhu Y (2007) A study on the method to identify large pore paths using conventional well logging data in sandstone reservoir. Period Ocean Univ China 37(3):463-468

Mohammed S, Wael H, Salah K et al (2010) Evaluating steam injection profile with high temperature memory PLT. In: Paper 128263-MS presented at the North Africa Technical Conference and Exhibition, Cairo

Saaty TL (1980) The analytic hierarchy process. McGraw Hill, New York 
Saaty TL (1988) The analytic hierarchy process. RWS Publications, Pittsburgh

Saaty TL (1994) Highlights and critical points in the theory and application of the analytic hierarchy process. Eur J Oper Res 74:426-447

Serres-Piole C, Preud'homme H, Moradi-Tehrani N et al (2012) Water tracers in oilfield applications: guidelines. J Petrol Sci Eng 98-99:22-39

Wang J, Liu HQ, Wang ZL et al (2012a) Experimental investigation on the filtering flow law of pre-gelled particle in porous media. Transp Porous Med 94(1):69-86

Wang ZG, Chen J, Yang WZ et al (2012b) Study of two boxes analysis models of coupled thermal flow in heavy oil reservoirs and their application. Chin J Rock Mech Eng 31(5):1007-1015

Wu YG, Dong MZ, Shirif E (2011) Study of alkaline/polymer flooding for heavy-oil recovery using channeled sandpacks. SPE Reservoir Eval Eng 14(3):310-319

Yang WZ, Song YC, Wang ZG et al (2012) Quantity study and numerical simulation on thermo-coupled mathematic model. J Eng Thermophys 33(2):277-281

Yi X (2002) Simulation of sand production in unconsolidated heavy oil reservoirs. J Can Pet Technol 41(3):11-13

Yoshiaki Ito (1984) The introduction of the microchanneling phenomenon to cyclic steam stimulation and its application to the numerical simulator (sand deformation concept). SPE J 24(4):417-430
Yu CL, Lin CY, Yin YS (2009) Quantitative identifying method for channeling path growing area in reservoirs of commingled injection and production. J China Univ Petrol (Edn Nat Sci) 33(2):23-28

Yuan AW, Ma H, Yang XY et al (2010) Research into steam overlay pattern and countermeasures for block Du84 in Liaohe oilfield. SPE 130947-MS

Zhang R (1999) Thermal recovery technology of heavy oil reservoir. Petroleum Industry Press, Beijing, pp 451-457

Zhang Y, Zhang YH, Sun XD (2002) Analysis of steam channeling mechanism in cyclic steam stimulation of super heavy oil in block Du84 and research of anti-channeling measures. Special Oil Gas Res 9(6):31-36

Zhang HL, Liu HQ, Wang $\mathrm{H}$ et al (2007) Optimization design of profile control parameters for steam stimulation wells. Acta Petrolei Sinica 28(2):105-108

Zheng Q, Liu HQ, Li F et al (2012) Quantitative identification of steam breakthrough channel after steam flooding in heavy oil reservoirs. SPE 156989-MS 